\title{
O produto interno bruto do Brasil ajustado pela depreciação do solo agrícola
}

\author{
Brazilian gross domestic product adjusted by the depreciation of \\ agricultural soil
}

Wladimir Colman de Azevedo Junior ${ }^{1}$ (D), Antônio Cordeiro de Santana² (i)

${ }^{1}$ Faculdade de Economia, Programa de Pós-graduação em Economia, Universidade Federal de Mato Grosso (UFMT), Cuiabá (MT), Brasil. E-mails: azevedocolman@gmail.com

${ }^{2}$ Núcleo de Altos Estudos Amazônicos, Programa de Pós-graduação de Doutorado em Desenvolvimento Sustentável do Trópico Úmido, Universidade Federal do Pará (UFPA), Belém (PA), Brasil. E-mail: acsufra@gmail.com

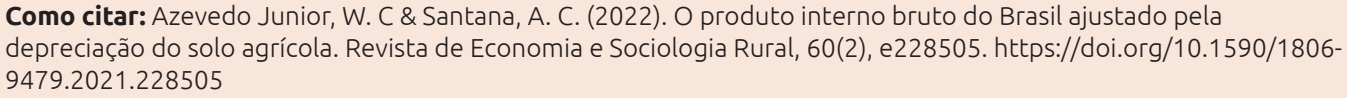

Resumo: A contabilização da depleção dos ativos ambientais, que servem como suporte ao crescimento econômico, tem permitido a consideração do passivo ambiental na mensuração do Produto Interno Bruto Ajustado Ambientalmente (PIBA). Busca-se mensurar a depleção causada no ativo ambiental solo, no que se refere ao balanço de NPK e seu impacto sobre a produção nacional. Os fluxos de entrada e saída de nutrientes foram monetizados e introduzidos na Matriz de Contabilidade Social e Ambiental do Brasil para 2010. Ao representar uma externalidade negativa, o saldo positivo do Balanço Monetário de Nutrientes do solo permitiu a estimação do PIBA brasileiro inferior ao PIB em R 4.176 milhões. Pode-se afirmar também que, a cada incremento de um milhão de reais das exportações de produtos agropecuários, os demais setores produtivos são induzidos ao aumento da produção que somaria R\$5.329,5 mil. No entanto, esse aumento da produção causaria a redução da fertilidade do solo equivalente a R $\$ 10.760,69$ que é totalmente reposta pelos dispêndios na aplicação de nutrientes.

Palavras-chave: Produto Interno Bruto ajustado ambientalmente, meio ambiente e crescimento, contas ambientais, Matriz de Contabilidade Social, depleção do solo.

\begin{abstract}
Accounting for the depletion of environmental assets, which it uses to support economic growth, is allowed to consider environmental passivity in the measurement of the Green Gross Domestic Product (GGDP). The aim is to measure the depletion affected in the active environmental soil, regarding the NPK balance and its impact on national production. Nutrient inflows and outflows were monetized and introduced into the Brazilian Social and Environmental Accounting Matrix for 2010. By representing a negative externality, the positive balance of the Soil Nutrient Balance of the soil allowed the application of Brazilian GGDP below GGDP at R\$4,176 million. It can also be stated that, for each increase of one million reais in the export of agricultural products, the other productive sectors are induced to increase production that would amount to $\mathrm{R} \$ 5,329.5$. However, this increase in production may lead to a reduction in soil fertility equivalent to $R \$ 10,760.69$, which is fully replaced by nutrient application devices.
\end{abstract}

Keywords: green gross domestic product; environment and growth; environmental accounts; social accounting matrix; soil depletion.

\section{Introdução}

Ao considerar o histórico produtivo das principais lavouras brasileiras', responsáveis pelo uso de $73 \%$ da área colhida e por $93 \%$ do valor produzido no setor agrícola nacional em 2015, observa-se um incremento médio de 36,6\% na produtividade, ao longo da década de 1990. Durante a década seguinte, essa produtividade cresce $33,3 \%$ e totaliza com aumento de $93 \%$ da

Considerando as principais lavouras: soja, milho, algodão, tomate, feijão, cana-de-açúcar, café, trigo, arroz, fumo, batata, laranja e banana. 
produção por hectare, entre 1990 e 2015 (Instituto Brasileiro de Geografia e Estatística, 2016b; Sousa et al., 2007). Concomitantemente, o uso de fertilizantes inorgânicos foi acrescido em 27,7 milhões de toneladas, no mesmo período. Em 2015, as principais lavouras demandaram $91 \%$ dos fertilizantes entregues. A década de 1970 apresentou o maior crescimento da demanda por fertilizantes no período, cerca de 257\% (Associação Nacional para Difusão de Adubos, 2016).

A significativa elevação da produtividade agrícola brasileira suscita a reflexão acerca da importância do setor sobre o crescimento econômico nacional. Neste sentido, Kuznets (1968) destaca que o aumento da produtividade agrícola pode influenciar a produtividade de outros setores da economia por meio da redução do preço de alimentos e matérias-primas, também ao provocar a elevação da demanda de máquinas e equipamentos e das transferências intersetoriais relacionadas ao pagamento de impostos e a oferta de mão de obra, além de possibilitar a obtenção de divisas. Em trabalho recente, McArthur \& McCord (2017) concluem que a produtividade agrícola tende a contribuir para o crescimento econômico, por meio de mudanças na estrutura do trabalho e aumentando a produtividade total dos fatores.

A influência da agricultura no processo de crescimento econômico depende do aumento da produtividade, cujos efeitos são propagados por meio dos efeitos de encadeamentos para trás e para a frente, via interação com os setores situados a montante e a jusante (Santana, 1994; Zylbersztajn et al., 2015). Schultz (1965) afirma que o acesso a fatores de produção de alta tecnologia leva à mudança estrutural no campo, capaz de ampliar a produtividade e causar repercussões em toda a economia. McArthur \& McCord (2017) defendem o apoio estatal à adoção e atualização das tecnologias utilizadas no campo e destacam os fertilizantes químicos como os principais impulsionadores da produtividade agrícola.

Entretanto, o uso intensivo do solo tem provocado discussões relativas ao passivo ambiental que surgiria como uma externalidade inerente ao crescimento econômico pautado no aumento da produtividade no campo. Neste contexto, o uso de fertilizantes químicos influenciaria o crescimento econômico, à medida que contribui com o aumento da produtividade, pois completa o balanço de nutrientes, necessários ao máximo desempenho das plantas, mas também indicaria o nível de desgaste químico do solo, no caso de deficiência nutritiva, além de evidenciar danos ambientais provocados pelo excesso de nutrientes, como a eutrofização (Vitousek et al., 2009), a desertificação (Manzatto et al., 2002) e a inibição da absorção de determinados nutrientes (Meurer, 2006). Assim, tanto o excesso quanto a deficiência de nutrientes devem ser considerados um passivo ambiental. Um crescimento econômico que considere o fluxo de nutrientes do solo deve, portanto, buscar um equilíbrio entre os fluxos de entrada e de saída de nutrientes.

Em esforço para a contabilização deste tipo de degradação, a Organização das Nações Unidas (2014) elaborou o Sistema de Contas Econômicas e Ambientais Integradas (SCEA), de 2012, onde conceitua o solo como um recurso natural, utilizado na produção agrícola como um ativo imobilizado e os nutrientes como insumos do solo. Assim, dispêndios concernentes ao uso de fertilizantes, devem ser entendidos como: (i) reposição dos nutrientes necessários para a manutenção da fertilidade do solo; (ii) aplicação de nutrientes necessários para ampliar a fertilidade do solo. Ressalvados os casos em que o aumento da aplicação de fertilizantes ultrapassa a disponibilidade de sítios de carga dos coloides do solo, como descrito por Meurer (2006).

Neste trabalho, deduz-se a depleção do solo, do cálculo do PIB, de modo a permitir a estimação do Produto Interno Bruto Ambiental (PIBA) e mesurar a ligação entre o fluxo produtivo e o estoque de recursos naturais, neste caso, o solo agrícola. Contabilizam-se, portanto, os fluxos de entrada de nutrientes no solo agrícola, denominados, primeiramente, como investimentos 
no solo e que seriam adicionados ao cálculo do PIB, pois representariam um aumento da Formação Bruta de Capital Fixo (FBCF). A depleção do solo, termo utilizado para identificar a depreciação de recursos naturais, seria registrada como fluxo de saída de nutrientes do solo, sendo deduzida do PIB, pois representaria um dispêndio necessário para a recuperação do nível de produção do solo e não um investimento em FBCF (Stiglitz et al., 2009).

Assim, em que pese a complexidade do ativo natural do solo, dada a gama de áreas da ciência necessárias para a compreensão dos seus aspectos físicos e químicos (Alleoni et al., 2016; Andrade, 2016; Ferreira, 2010), a depleção é entendida, neste trabalho, somente por sua dimensão química e será trabalhada por meio do conhecimento agronômico referente aos fluxos físicos de macronutrientes verificados na camada agricultável do solo e do conhecimento econômico no que se refere à monetização desses fluxos para a estimativa do PIBA. A depleção química do solo, portanto, pode ser entendida como a perda gradual de nutrientes, por meio da extração realizada pelas plantas e que deve ser reposta via entrada de nutrientes no solo, pela aplicação de fertilizantes, com vistas a retardar o esgotamento do solo e a manter a viabilidade econômica das lavouras. O saldo negativo, entre os fluxos de entrada e saída de nutrientes, é contabilizado como uma depleção, ao passo que o saldo positivo representa um excesso de nutrientes que pode configurar um acréscimo no estoque de nutrientes ou engendrar uma externalidade negativa.

Desse modo, pretende-se responder os seguintes questionamentos: Qual o impacto do dispêndio direcionado à recuperação da fertilidade do solo sobre o estoque de capital brasileiro? Qual o impacto do fluxo produtivo do setor agropecuário sobre a fertilidade do solo? Quer-se, aqui, a inclusão do processo de degradação química dos solos agrícolas nas contas nacionais. Este artigo objetiva quantificar a magnitude do passivo químico gerado por meio do uso dos solos com a agricultura no Brasil, em que os sistemas de manejo, característicos do agronegócio nacional, são dependentes da aplicação dos pacotes oferecidos por empresas de fertilizantes e defensivos agrícolas.

Este estudo contribui ao propor a inclusão do desgaste químico do solo nas contas nacionais por meio da monetização dos fluxos de macronutrientes. A utilização da Matriz de Contabilidade Social permitirá não só a quantificação do impacto da produção agregada sobre o desgaste do solo (expressa por meio do PIBA) como possibilitará a estimação do impacto relativo ao aumento da produção de outros setores sobre o desgaste do solo.

Considerando a literatura disponível e a tendência ao aumento do consumo de fertilizantes, dado o aumento da produtividade agrícola, a hipótese deste trabalho é que parte da depleção do solo nacional não é reposta, pois a extração de nutrientes durante o cultivo seria superior à reposição garantida pela aplicação de fertilizantes, de tal modo que, ao subtrairmos a depreciação do total investido, gera-se um saldo negativo que deveria ser subtraído do PIB. Desta feita, a Matriz de Contabilidade Social Ajustada Ambientalmente do Brasil para 2010, incluindo o desgaste químico, foi construída para estimar o PIBA e extrair indicadores dos impactos da produção sobre o solo.

Este manuscrito foi estruturado em 4 seções, além da introdução. A seção a seguir, que dispõe a revisão de literatura, foi dividida em duas partes, a primeira apresenta o PIB ambiental e a segunda demonstra a dinâmica de nutrientes no solo. A seção posterior descreve como a depleção química do solo foi obtida, bem como o cálculo do PIBA. A seção de resultados apresenta e discute as consequências da inclusão da depleção química do solo na inferência do PIB. As principais conclusões são dispostas na última seção. 


\section{Revisão de literatura}

Essa seção é dividida em quatro subseções. As duas primeiras dispõem a literatura concernente à confecção do PIBA de modo a respaldar, do ponto de vista econômico, a inclusão da depleção química do solo na estimação do PIBA brasileiro. As duas últimas subseções fornecem a construção lógica e empírica que permite quantificar e monetizar, o fluxo de nutrientes do solo agrícola nacional.

\subsection{Produto interno bruto ambiental (PIBA)}

O Produto Interno Bruto (PIB) permite estimar a totalidade dos bens e serviços finais produzidos por um país. O procedimento metodológico de estimação do PIB é padronizado por meio do manual do Sistema de Contas Nacionais (SCN), de autoria da Organização das Nações Unidas (Organização das Nações Unidas, 2009). Por meio do Sistema de Contas, é possível extrair variáveis macroeconômicas que permitem mensurar, entre outras coisas, o crescimento econômico nacional, o nível de investimento e o estoque de produtos, além de fornecer os dados necessários para a elaboração da Matriz de Insumo-Produto (MIP) e da Matriz de Contabilidade Social (MCS) (Feijó \& Ramos, 2017).

A contabilização dos esforços nacionais para a produção de bens e serviços tem início em 1947, quando a ONU, liderada por Richard Stone, publica seu primeiro relatório sobre o assunto. Com o objetivo de permitir que a mensuração fosse padronizada na maior parte dos países, a instituição publica atualizações em 1953, 1960, 1964, 1968, 1993 e 2008. Essas atualizações vislumbravam permitir a mensuração do PIB por países com distintas complexidades e para que essas informações apresentassem melhor harmonização com outros dados, como a balança de pagamentos, estatísticas relacionadas às finanças públicas, contas monetárias e dados relativos ao trabalho (Paulani \& Braga, 2012).

Segundo Haripriya (2001), somente após a criação de um sistema satélite, incorporado ao SCN de 1993, é que os recursos naturais passam a integrar o Sistema de Contas. Em 2014, a Organização das Nações Unidas (2014) publica o Sistema de Contas Econômicas e Ambientais (SCEA) de 2012, em que se apresenta uma forma padronizada de interligação entre os fluxos produtivos e o uso dos recursos naturais. O SCEA 2012 apresenta uma série de conceitos, contas e recomendações relativos à economia e à ecologia, com o intuito de estabelecer um arcabouço teórico-técnico específico a cada recurso natural abordado e que deve ser seguido pelos países, a fim de se obter um padrão na concepção das contas ambientais. Nesse contexto, surge o conceito do Produto Interno Líquido Ajustado Ambientalmente (PILA) que resulta da subtração da depreciação dos recursos naturais do Produto Interno Líquido (PIL). Entretanto, devido à indisponibilidade do PIL, as pesquisas relacionadas têm utilizado o Produto Interno Bruto Ambiental (PIBA), que resulta da subtração da depreciação dos recursos naturais do Produto Interno Bruto. O manual denomina por depleção a depreciação ambiental. O cálculo do PIBA torna-se possível por meio da introdução da exaustão dos recursos naturais, renováveis e não renováveis, no Sistema de Contas Nacionais.

Essa introdução depende da mensuração dos fluxos de desgaste e reposição dos recursos naturais e deve ser feita de forma individual para cada tipo de recurso, de modo a respeitar suas especificidades (Organização das Nações Unidas, 2014). O Sistema de Contas Econômicas e Ambientais para a Água (SCEAA) é um esforço realizado pela Organização das Nações Unidas (2012) para quantificar o uso da água. A Conta Satélite da Água, mensurada no Brasil, por exemplo, é baseada no SCEAA e estima as adições ao estoque de água superficial, do solo e subterrâneas, por meio das variáveis de precipitação pluviométrica, entrada de outros países e 
a subtração por meio da captação, da evaporação, da saída para outros países e para o mar. 0 SCEAA também foi utilizado para estimação da conta da água na Holanda (Edens \& Graveland, 2014), na Colômbia (The World Bank, 2017), em Botswana (Setlhogile et al., 2017), na Espanha (Gonzalez et al., 2016; Morilla et al., 2007), na Itália (Mazzanti et al., 2014), na Dinamarca, na Islândia, na Suécia e na Noruega (Lindhjem et al., 2009).

Embora não disponham de manuais específicos, como no caso da água, pesquisas relativas a outros recursos naturais têm utilizado a metodologia presente na SCEA 2012 para a mensuração e a incorporação de outros ativos. Em relação à degradação da floresta na Índia, existem os trabalhos de Gundimeda et al. (2007) e Haripriya (2001) e, na Guatemala, o trabalho de Banerjee et al. (2017). A depleção do ar, causada pela emissão de $\mathrm{CO}^{2}$, foi objeto de análise na Costa Rica (Vardon et. al, 2017), na Colômbia (Maldonado \& Lachaud, 2011), na Dinamarca, na Islândia, na Suécia e na Noruega por Lindhjem et al. (2009). Nos EUA, Dvarskas (2018) propôs uma técnica de mensuração dos impactos das atividades econômicas sobre o ecossistema marinho. No Brasil, Lenzen \& Schaeffer (2004) analisaram o uso de energia e a emissão de carbono em comparação à geração de emprego e renda.

Em relação ao solo, o SCEA apresenta as definições de terra e de recursos do solo. A terra é o espaço delineado para a ocorrência das atividades econômicas e dos processos ambientais, dentro do qual estão inseridos os ativos ambientais e econômicos. As contas da terra têm como objetivo identificar a distribuição da terra disponível entre as atividades econômicas e o meio ambiente (Organização das Nações Unidas, 2014). Esse tipo de conta foi citado por Lindhjem et al. (2009) como importante para a captação dos impactos da agropecuária no conjunto de países nórdicos. O Instituto Brasileiro de Geografia e Estatística (2020) utiliza a Conta de Uso da Terra nos Biomas Brasileiros para contabilizar o estoque atual para cada tipo de uso e suas variações.

Os recursos do solo, por sua vez, são os recursos ambientais, presentes nos primeiros $20 \mathrm{~cm}$ do perfil do solo, necessários para sustentar a produção agropecuária, como os nutrientes, a água do solo e o teor de carbono, além de fornecer base para construções, habitat para diversos organismos e ofertar serviços ambientais como a regulação da temperatura, o fornecimento de água e a ligação de agentes químicos e biológicos. As contas do solo, portanto, têm como objetivo mensurar os fluxos de nutrientes, de carbono, de água e de outras características físicas, químicas e biológicas, permitindo a conexão contábil entre a utilidade do solo e a produção agrícola (Organização das Nações Unidas, 2014).

As publicações que têm os recursos do solo como objeto de estudo consideram o seu aspecto físico, como fizeram Repetto et al. (1989), para a Indonésia onde a degradação física do solo foi estimada por meio da monetização das perdas de solo causadas por erosão, concluindo que, a cada dólar investido na produção presente, cerca de quarenta centavos de dólar da renda futura são perdidos, considerando o manejo praticado à época. No México, Tongeren et al. (1991) incluíram a erosão, o depósito de resíduos sólidos e o uso da água superficial em um indicador contendo a degradação de outros recursos naturais, revelando que a economia mexicana recupera apenas $23,26 \%$ de todo o desgaste ambiental mensurado no trabalho.

Os conceitos e metodologias relacionados à mensuração do uso dos ativos naturais, disponíveis no SCEA 2012, têm sido aplicados para a obtenção do PIBA por meio da Matriz de Contabilidade Social e Ambiental (MCSA). O avanço da MCSA em relação à estimação por meio do SCN é o cálculo da interrelação entre os setores institucionais, que, por sua vez, permite o cômputo do impacto da produção setorial sobre o recurso ambiental. Nesse sentido, Lenzen \& Schaeffer (2004) construíram a MCSA para o Brasil para 1995 e encontraram uma correlação inversa entre a geração de emprego e renda com o uso de energia e a emissão de carbono, 
além de uma correlação positiva entre energia e carbono com as importações. Brasileiro (2012) tentou estimar o PIBA da Amazônia Legal por meio da MCSA, entretanto a ausência de dados levou ao uso da matriz de insumo-produto (MIP). Como resultado, o PIBA encontrado foi inferior, em 15\%, ao PIB.

No Chile, Mardones \& Saavedra (2011) utilizaram a Matriz de Contabilidade Social Ajustada Ambientalmente (MCSA) para estimar os impactos dos setores da economia regional sobre a contaminação do ar e da água e concluíram que os principais setores poluidores são as indústrias de produção de papel, metal, além da geração de eletricidade e da extração de gás e água e do setor de transporte. Na Colômbia, em estudo conduzido por Maldonado \& Lachaud (2011), estimou-se uma queda de $1 \%$ na taxa de crescimento, quando considerada a depleção de $\mathrm{CO}_{2}$ e de gás natural, revelando o impacto da produção atual sobre a produção futura.

Gundimeda et al. (2007) também avaliaram o impacto da produção sobre as florestas para a Índia e seus estados, tendo, como conclusão, a subestimação da contribuição da floresta na geração de renda nacional. Em outro estudo, no mesmo país, Haripriya (2001) encontrou um PIBA 1,6\% menor que o oficial entre os anos de 1993 e 1994. Também mensurando a depleção florestal, Banerjee et al. (2017) avaliaram seu impacto sobre a economia da Guatemala, principalmente por causa do uso incorreto da madeira como combustível. Ao estimar a degradação dos recursos hídricos e a emissão de gases de efeito estufa, por meio da MCSA para a Espanha no ano de 2000, Morilla et al. (2007) concluíram que não existe relação causal entre os setores que produziram maior valor agregado e aqueles que provocam maior deterioração ambiental, sendo possível, portanto, a adoção de políticas de mitigação dos impactos sobre os recursos avaliados.

\subsection{Matriz de contabilidade social e ambiental (MCSA)}

A MCSA deriva da Matriz de Contabilidade Social (MCS). Essa pode ser entendida como uma generalização do Sistema de Contas Nacionais (SCN), tendo como principal contribuição a incorporação das transações e transferências entre instituições relacionadas à distribuição de renda na economia. Segundo Miller \& Blair (2009), a MCS surge da combinação do SCN que, baseando-se no fluxo circular da renda, fornece uma estrutura padronizada que permite compilar e organizar estatísticas nacionais, com a matriz de insumo-produto, que incorpora a atividade intersetorial. A MCS considera, ainda, as ações realizadas pelas famílias que, como detentoras dos fatores de produção, recebem a remuneração e dos agentes institucionais que consomem a produção (Pará, 2015).

A MCS descreve, portanto, o fluxo circular da renda, à medida que torna endógeno o vínculo entre produção e renda e entre a renda e o consumo (Santana, 2005). Esses vínculos se referem às contas de geração e de alocação da renda, respectivamente, que compõem as Contas Econômicas Integradas (CEI) do SCN brasileiro, Instituto Brasileiro de Geografia e Estatística (2016b). A adição de dados ambientais permite que a depleção do solo seja considerada. Neste sentido, a Matriz de Contabilidade Social ambiental (MCSA) é conceitualmente apresentada contendo cinco contas endógenas dispostas em blocos matriciais, além de duas contas exógenas, conforme a Tabela 1.

Os dados fornecidos na matriz de demandas intermediárias da MIP são organizados na conta de Atividades Produtivas (Ta) da MSC, tendo o mesmo significado e aplicação. O Valor Adicionado (Tv) constitui a segunda conta e dispõe o salário e o lucro (Miller \& Blair, 2009). A depleção do solo ( $D$ solo) é lançada com sinal negativo, pois representa uma perda de bem-estar econômico, conforme preconizado pela Organização das Nações Unidas (2014), 
Tabela 1 - Estrutura da Matriz de Contabilidade Social.

\begin{tabular}{|c|c|c|c|c|c|c|c|}
\hline \multirow[b]{3}{*}{ MCS } & \multicolumn{5}{|c|}{ Conta endógena } & \multicolumn{2}{|l|}{ Conta exógena } \\
\hline & \multirow[b]{2}{*}{$\begin{array}{l}\text { Vetores } \\
\text { Prod. }\end{array}$} & \multicolumn{3}{|c|}{ Instituições } & Valor Adicionado & \multirow[b]{2}{*}{ Imposto } & \multirow[b]{2}{*}{ RT } \\
\hline & & Governo Famílias & $\begin{array}{c}\text { Empresas } \\
\text { FBCF }\end{array}$ & $\begin{array}{l}\text { Empresas } \\
\text { FBCNF } \\
\text { Solo }\end{array}$ & Salário Lucro D solo & & \\
\hline $\begin{array}{l}\text { Atividade } \\
\text { Produtiva }\end{array}$ & $\mathrm{Ta}$ & & Tc & & 0 & $\mathrm{Xa}$ & Ya \\
\hline Instituições & 0 & & $\mathrm{Ti}$ & & $\mathrm{Tr}$ & $\mathrm{Xi}$ & Yi \\
\hline $\begin{array}{l}\text { Valor } \\
\text { adicionado }\end{array}$ & Tv & & 0 & & 0 & $X v$ & Yv \\
\hline $\begin{array}{l}\text { Connta } \\
\text { Exógena }\end{array}$ & Ea & & $\mathrm{Ei}$ & & Ev & Z & $Y j$ \\
\hline $\begin{array}{l}\text { Valor da } \\
\text { Produção }\end{array}$ & Ya & & Yi & & Yv & $Y j$ & Yt \\
\hline
\end{tabular}

Ta é a matriz de atividades produtivas, ou intersetoriais; Tv é a matriz de valor adicionado; Tr é a matriz de apropriação da renda pelas instituições; Ti registra as transaç̃̃es entre os setores institucionais; Tc revela o consumo dos setores da renda das, instituiç̃es: Xy é o vetor exónas. Xa é o vetor exógeno de demanda por produtos; Xi é o vetor exógeno da renda das instituições; Xy é o vetor exogeno do valor adicionado. Ya e o vetor total de produção das indústrias; Yi é o vetor total das rendas; Yv é o vetor total do valor adicionado; Yj é o vetor total exógeno. FBCF é a formação bruta de capital fixo; FBCNF solo é a formação bruta de capital natural fixo do solo agrícola, que se refere à aplícação de nutrientes no solo; D solo é a depleção do solo agrícola causada pela extração de nutrientes pelo cultivo. Com. Int. é
o resultado do comércio exterior. RT é a receita total.

Fonte: Elaborada pelo autor, a partir de Santana (2005) e Marcos et al. (2009).

aqui representado pelo déficit do balanço do fluxo de macronutrientes, utilizado na produção agrícola anual, sem considerar as externalidades ambientais nos serviços e na formação dos solos manejados com as práticas utilizadas nos sistemas de commodities agrícolas no Brasil.

A apropriação da renda pelas Instituições (Tr) descreve como o valor adicionado é distribuido entre as famílias, o governo e as empresas. As transferências, entre os próprios setores institucionais, são registradas na conta de Distribuição (Ti), que permite o vínculo com a conta de Consumo (Tc) das instituições de produtos confeccionados pelas Atividades Produtivas ( $\mathrm{Ta}$ ). Nesta última conta, é mensurado o consumo total das famílias, do governo e das empresas (investimento), por produto (Santana, 1994). Aqui também foi incluído o montante despendido em investimento na fertilidade do solo (FBCNF solo), conforme Organização das Nações Unidas (2014). As contas exógenas (Z) são matematicamente necessárias para permitir que a matriz seja invertível, podendo, assim, produzir os seus multiplicadores (Round, 2003).

Além dos blocos matriciais, pode-se identificar os vetores $X a, X y$ e Xi que se referem, respectivamente, à demanda por produtos, valor adicionado e à renda das famílias, exogenamente especificados. Os vetores endógenos Ya, Yy e Yi representam o valor total de produção, o total do valor adicionado e o total da renda das famílias, respectivamente.

No Brasil, Urani et al. (1994) construíram a MCS e propuseram seu uso para balisar a tomada de decisão macroeconômica. Santana (1994) utilizou essa matriz para relacionar o complexo agroindustrial com o crescimento brasileiro. Em outro trabalho, Marcos et al. (2009) identificaram os fatores que explicam a queda da desigualdade de renda brasileira entre 2004 e 2009. A diferença entre a MCS e a MCSA se dá na inclusão de variáveis ambientais. Nesse sentido, no nível nacional, somente Lenzen \& Schaeffer (2004) produziram a MCSA. Nenhum desses trabalhos estimou a MCSA utilizando o solo como recurso natural a ser avaliado. Portanto, esta é a inovação deste artigo que permitirá a estimação do PIBA utilizando a depleção nutricional do solo agrícola nacional e a produção de indicadores que relacionam a atividade econômica à degradação do solo no Brasil. Um resumo das publicações já citadas pode ser visto na Tabela 2 que reforça o caráter inovativo citado. 
Tabela 2 - Os recursos naturais entendidos como capital natural na literatura científica.

\begin{tabular}{|c|c|c|c|c|c|c|}
\hline Artigo & País & Abrang. & PIBA & Período & Ajust. & SCEA \\
\hline Mardones \& Saavedra (2011) & Chile & Regional & $x$ & 1996-2006 & Ar e água & $\checkmark$ \\
\hline Brasileiro (2012) & Brasil & Regional & $\checkmark$ & 2004 & Ar & $\checkmark$ \\
\hline Tongeren et al. (1991) & México & Nacional & $x$ & 1990-1991 & $\begin{array}{l}\text { Petróleo, } \\
\text { floresta, } \\
\text { terra e ar }\end{array}$ & $\checkmark$ \\
\hline Dvarskas (2018) & EUA & Regional & $x$ & 2006 e 2011 & $\begin{array}{l}\text { Recursos } \\
\text { marinhos }\end{array}$ & $\checkmark$ \\
\hline Maldonado \& Lachaud (2011) & Colômbia & Nacional & $\checkmark$ & 1995-2005 & $\begin{array}{c}\text { Gás natural } \\
\text { CO2 }\end{array}$ & $x$ \\
\hline Gundimeda et al. (2007) & Índia & N/R & $\checkmark$ & $2001-2003$ & Florestas & $\checkmark$ \\
\hline Haripriya (2001) & Índia & Nacional & $\checkmark$ & 1993-1994 & Florestas & $\checkmark$ \\
\hline Banerjee et al. (2017) & Guatemala & Nacional & $x$ & $2013-2025$ & Florestas & $\checkmark$ \\
\hline Edens \& Graveland (2014) & Holanda & Nacional & $x$ & 2010 & Água & $\checkmark$ \\
\hline Setlhogile et al. (2017) & Botswana & Nacional & $x$ & 2010-2015 & Água & $\checkmark$ \\
\hline Gonzalez et al. (2016) & Espanha & Regional & $x$ & 1980-2006 & Água & $\checkmark$ \\
\hline Gutiérrez-Martín et al. (2017) & Espanha & Regional & $x$ & 2004-2012 & Água & $\checkmark$ \\
\hline Mazzanti et al. (2014) & Itália & Regional & $x$ & 1999-2013 & Água & $\checkmark$ \\
\hline Brasil (2018) & Brasil & Nacional & $x$ & 2013-2015 & Água & $\checkmark$ \\
\hline Repetto et al. (1989) & Indonésia & Nacional & $x$ & 1970-1984 & $\begin{array}{l}\text { Floresta, } \\
\text { Petróleo e } \\
\text { erosão do } \\
\text { solo }\end{array}$ & $\checkmark$ \\
\hline Lenzen \& Schaeffer (2004) & Brasil & Nacional & $x$ & 1995 & $\begin{array}{c}\text { Energia e } \\
\mathrm{CO}^{2}\end{array}$ & $\checkmark$ \\
\hline Morilla et al. (2007) & Espanha & Nacional & $x$ & 2000 & Água e $\mathrm{CO}^{2}$ & $\checkmark$ \\
\hline
\end{tabular}

Fonte: Elaborado pelo autor.

A partir da MCSA, pode-se estimar efeitos distintos sobre a economia. Conforme proposto por Pyatt \& Round (1979), a partir de Stone (1985), matrizes calculadas a partir da MCSA revelam os efeitos totais do incremento da demanda exógena sobre a economia. O aumento da demanda exógena de produtos da agropecuária pode apresentar um efeito de transferência, à medida que este setor transfere, para outros setores, o estímulo inicial por meio da aquisição de insumos. No entanto, os outros setores, ao reduzirem sua capacidade ociosa, consomem mais insumos, inclusive aqueles ofertados pelo setor agropecuário, gerando um novo estímulo a este setor. Esse é o efeito circular. O mesmo aumento da demanda pode provocar um efeito cruzado, pois a elevação da produção agropecuária resulta em crescimento do valor adicionado que é apropriado pelas instituições que o utilizam para adquirir novos bens e serviços. A soma desses três efeitos dá vida ao efeito global, que sintetiza toda a repercussão entre setores, e entre setores e instituições, sendo mais completa que os coeficientes entregues pela MIP para representar as operações realizadas no fluxo circular de uma economia.

Guardando a relação entre a MSC e a MIP (Miller \& Blair, 2009), o cálculo desses efeitos baseia-se no fluxo circular que permite que um incremento anotado em um setor, instituição ou componente do valor agregado atinja todos os setores (Stone, 1985). O cálulo inicia-se na equação básica de Leontief para a matriz de insumo-produto, como na Equação 1 e tem como objetivo estimar a matriz de efeito global $(\mathrm{Mg})$, formada pelos demais efeitos (Santana, 2005). 


$$
\begin{aligned}
& X=A X+Y \\
& (I-A) X=Y \\
& X=(I-A)^{-1} Y
\end{aligned}
$$

A Equação 1 expressa a renda (Y), por setor, das atividades endógenas que resultam dos incrementos realizados na demanda (X), multiplicada pela matriz de efeitos globais (Santana, 2005). Tomando $M_{g}=(I-A)^{-1}$, tem-se (Equação 2):

$$
X=M_{g} Y
$$

Sabendo que o efeito global é mensurado por meio de outros três efeitos, é necessário decompô-lo para, então, estimar as matrizes de efeitos desejados. Segundo Pyatt \& Round (1979), isso se torna possível, a partir da repartição da matriz de coeficientes técnicos, em duas outras, as matrizes B e C. Stone (1985) exemplifica que, em um sistema no qual existam três subsistemas endógenos, a injeção aplicada a uma conta pertencente a um destes subsistemas pode se mover dentro do próprio subsistema, como mensurado na inversa de Leontieff e que se denomina efeito de transferência (MET), pode se deslocar por todos os subsistemas e retornar à conta inicial, como um efeito circular (MEC), ou pode se mover e acabar em um outro subsistema, efeito cruzado (MECZ).

Sabendo que Mg (Equação 3) é dado pelo produto de três multiplicadores, $M a_{1}$, que se refere ao efeito de tranferência, $M a_{2}$, que se trata do efeito cruzado, e $M a_{3}$, que se refere ao efeito circular, a equação básica de Leontieff pode ser redefinida como na Equação 4 (Stone, 1985).

$\mathrm{Mg}=\mathrm{Ma}_{1} \mathrm{Ma}_{2} \mathrm{Ma}_{3}$

Em que:

$$
\begin{aligned}
& M a_{I}=(I-B)^{-1} ; M a_{2}=\left(I+D+D^{2}\right) e M a_{3}=\left(I-D^{3}\right)^{-l} \\
& D=(I-B)^{-1}(A-B) \\
& Y=M a_{3} M a_{2} M a_{1} X
\end{aligned}
$$

Simplificando a análise, Stone (1985) fornece uma versão da Equação 3 em forma aditiva (Equação 5), em que o valor de cada um dos efeitos é subtraído da matriz uniária I que representa as injeções realizadas. Assim, os efeitos de transferência, cruzado e circular, levam à equação final do efeito global (5), em sua forma líquida da injeção e que pode ser decomposta nas Equações 6, 7, 8.

$$
\begin{aligned}
& M_{g}=I+\left(M a_{1}-I\right)+\left(M a_{2}-I\right) \cdot M a_{1}+\left(M a_{3}-I\right) M a_{2} M a_{1} \\
& M E T=M a_{1}-I
\end{aligned}
$$


$M E C=\left(M a_{3}-I\right) M a_{2} M a_{1}$

A estimação da MCSA para o Brasil permitirá o cálculo do PIBA para 2010, bem como a construção dos indicadores de efeitos de encadeamento entre os setores institucionais da economia brasileira, considerando o quanto cada um deles influirá no desgaste do solo nacional. Entretanto, é preciso estimar a depleção química do solo. Neste trabalho, esta estimação se baseará nos fluxos de entrada e saída de macronutrientes, conforme descrito na subseção a seguir.

Assim como a MCS, a versão ambiental desenvolvida neste trabalho é limitada pelas hipóteses inerentes ao modelo. As hipóteses mais restritivas são: os coeficientes serem considerados fixos e a rigidez dos preços, provocando a limitação das inferências para o contexto de curto prazo; a agregação das unidades produtivas em setores resultar na consideração teórica de que todas as unidades fabricam um produto homogêneo, assim, os coeficientes tecnológicos estimados são aplicáveis a todo o setor; considerar-se que todos os setores operam com capacidade ociosa, assim, conseguem responder a qualquer aumento da demanda.

\subsection{A dinâmica de nutrientes no solo.}

A interligação, entre a produção rural e os setores não agrícolas, é baseada na exploração dos recursos ambientais que conformam as condições necessárias para o cultivo agrícola. Em relação ao solo agrícola, ativo ambiental utilizado como suporte à produção e que está contido em um ecossistema local, o crescimento e o desenvolvimento das plantas dependem diretamente da qualidade física, química e biológica do solo. Em solos não sujeitados à intervenção antrópica, a qualidade dependerá do material de origem e do processo de intemperismo aos quais este é submetido (Meurer, 2006).

O processo de intemperismo leva à formação das fases sólida, líquida e gasosa do solo. Os minerais que emergem nas camadas agricultáveis formam os coloides que, ao se agregarem, criam os macroporos, ocupados pelo ar do solo, e os microporos, ocupados pela solução do solo. Além dos minerais, a fase sólida também é composta por material orgânico oriundo da liteira. A fase líquida é constituída por água, minerais e compostos orgânicos, sendo chamada de solução do solo, enquanto a fase gasosa é formada pelo ar do solo. A atividade biológica também é fundamental para a dinâmica do solo, pois permite, entre outras, a disponibilidade de nutrientes, por meio da quebra de moléculas maiores, como é o caso da Fixação Biológica de Nitrogênio. Essa dinâmica ecossistêmica entre as três fases do solo e da atividade biológica é que permite a absorção de nutrientes e a recuperação da qualidade do solo (Meurer, 2006).

A interface coloide-solução do solo é a responsável pelo armazenamento e disponibilização dos elementos químicos essenciais às plantas. Oriundos do processo de formação do solo, em que elementos químicos são liberados pelo intemperismo, os nutrientes são adsorvidos pelos coloides e só podem ser absorvidos pelas raízes, após a dessorção e consequente disponibilização na solução do solo (Meurer, 2007). As trocas de elementos, realizadas entre a solução e a fase sólida, devem-se à tendência de equilíbrio de cargas nas duas fases. A absorção de nutrientes, pelas plantas, reduz a concentração destes na solução. O reequilíbrio é reestabelecido após a dessorção dos mesmos elementos. No entanto, esse reequilíbrio da solução do solo custa o desequilíbrio de cargas na superfície dos coloides. Por meio da decomposição da liteira, os nutrientes absorvidos retornam ao solo, provocando o reequilíbrio da solução e dos coloides (Andrade, 2016). 
A resiliência do solo é definida por essa dinâmica ecossistêmica, o que permite a equalização das entradas e saídas de nutrientes de tal modo que não se observe sua degradação. No entanto, em solos antrópicos, essa dinâmica é alterada, pois não atende à eficiência exigida pelo mercado. A produção suportada e o tempo de recuperação da fertilidade do solo para o próximo uso não condizem com a produtividade e com os períodos de produção expectados.

Em solos sob agricultura intensiva, baseada na monocultura e no uso dos pacotes tecnológicos mais avançados, a exportação de nutrientes devida à absorção pelas variedades cultivadas ultrapassa a capacidade de resiliência do solo. Ao contrário do observado em solos sem intervenção, o reequilíbrio de cargas se dá por meio do aumento da adsorção de $\mathrm{H+}$, tendo como efeito a elevação da acidez e a consequente redução das cargas negativas presentes na superfície dos coloides. A aplicação de fertilizantes, portanto, teria, como finalidade primária, equiparar a quantidade exportada de nutrientes, a fim de evitar a ocorrência do desequilíbrio de cargas (Meurer, 2006).

A maior parte dos solos brasileiros é formada por argilominerais do tipo 1:1, cujas cargas superficiais são $\mathrm{pH}$ dependentes, por isso, a quantidade de cargas negativas disponíveis para adsorção de nutrientes depende do nível do pH. Desse modo, o aumento da acidez reduz os sítios de carga disponíveis para a adsorção de nutrientes, enquanto a redução da acidez origina cargas negativas, pois induz a dessorção de $\mathrm{H}+$ e a adsorção de $\mathrm{OH}$ - (Meurer, 2006). A fertilidade do solo depende, portanto, do predomínio de cargas negativas. Como a maior parte dos elementos essenciais são cátions, o pH dos latossolos brasileiros agricultáveis tende a variar entre 5,7 e 6,0, de modo que ocorra predominância de cargas negativas nos coloides (Sousa et al., 2007).

O uso intensivo do solo, pode provocar a redução de sua fertilidade, prejudicando os rendimentos do produtor e acelerando o processo de acidificação do solo. Nessa situação, o uso de fertilizantes só seria eficaz após a calagem, pois, sem sítios de carga disponíveis, os nutrientes tendem a lixiviar, atingindo a água do subsolo (Meurer, 2006). Nesse sentido, ao estudarem o solo africano, Cobo et al. (2010) revelaram a possibilidade de acidificação do solo agrícola, devido à falha na reposição de nutrientes. No Paraná (Ciotta et al., 2002) e em Minas Gerais (Lange et al., 2006), foram identificadas alterações no pH, mesmo com o uso do plantio direto.

Nesse sentido, o Sistema de Contas Econômicas e Ambientais conceitua o solo como um capital natural que integra a riqueza nacional. A contribuição da agricultura para o crescimento econômico custaria parte do estoque de capital natural nacional compreendido pela fertilidade do solo. O solo é entendido, portanto, como um estoque de capital imobilizado para a produção agrícola. Assim, como se verifica na depreciação de máquinas e equipamentos do processo produtivo, o solo pode se desgastar, tornando-se inapto para a produção (Organização das Nações Unidas, 2014).

A aplicação dos fertilizantes é a forma de recuperar a fertilidade desse capital natural e continuar produzindo em alta produtividade. Essa aplicação pode exceder a quantidade exportada de nutrientes pelo cultivo anterior, sendo esse excedente considerado um investimento, pois resulta em fertilidade superior à registrada anteriormente. Deve-se, no entanto, atentar-se aos limites dados pela quantidade de sítios de carga disponíveis para a adsorção dos nutrientes aplicados.

Como afirma Meurer (2006), a aplicação de fertilizantes além da quantidade de suporte do solo pode elevar a concentração na água do solo. Como resultado, além de prejudicar o desenvolvimento das plantas, que tendem a absorver quantidade superior à própria necessidade e a ter a absorção de outros nutrientes comprometida (Meurer, 2007), a quantidade excessiva 
de nutrientes pode lixiviar e escoar com a água, alterando a estrutura do solo abaixo da camada agricultável e, assim, provocar a redução do valor ecológico do solo quando comparado a seu estado original, além de atingir lagos e rios próximos (Meurer, 2006). Essa contaminação da água é indicada por Vitousek et al. (2009) como o motivo da eutrofização ocorrida no Golfo do México, em decorrência do excesso de nitrogênio $(N)$ e fósforo $(P)$ aplicado pela agricultura.

Resultado semelhante foi encontrado no Brasil, onde Silva et al. (2018) encontraram um grau elevado de contaminação, por $\mathrm{N}$ e $\mathrm{P}$, o que inviabilizou o uso da água para o consumo humano em um reservatório no Ceará. A morte de peixes, devido à alteração do ambiente aquático provocada pelo excesso de nutrientes, foi observada no Espírito Santo, em 2016 $(G 1,2016)$, e no rio Tietê, em São Paulo $(G 1,2018)$. As emissões atmosféricas de óxido nitroso também são apontadas como resultantes do excesso de $\mathrm{N}$ no solo (Organização das Nações Unidas, 2014). O excesso de $\mathrm{KCl}$ deixa o solo mais suscetível à salinidade e, consequentemente, à desertificação (Manzatto et al., 2002)

O excesso e a falta de nutrientes no solo, portanto, representam perigo à eficiência produtiva, à segurança alimentar e ao meio ambiente, exigindo atenção de governantes e de produtores (Vitousek et al., 2009). Ao entendermos o solo como um capital imobilizado para a produção agrícola e reconhecermos a necessidade da gestão de nutrientes, torna-se necessário mensurar os fluxos de entrada e saída de nutrientes no solo. Sobre essa mensuração é que tratará a subseção a seguir.

\subsection{Os balanços físico e monetário de nutrientes do solo}

Alguns trabalhos científicos foram direcionados à quantificação do fluxo de nutrientes e à obtenção do saldo após a safra. Sheldrick et al. (2003) estudaram o balanço de nitrogênio, fósforo e potássio na China, entre 1961 e 1997, utilizando o modelo de auditoria de nutrientes. Posteriormente, Chen et al. (2016) utilizaram o Elementary Unit basednutrient Balance ModeLing in Agro-ecosystem (Eubolism), que consiste na construção de um fluxograma e equações que contabilizam a entrada e a saída observadas nos nós de ligação entre as diferentes fontes do nutriente e atividades agrícolas, para avaliar a eficiência agrícola chinesa em relação ao uso de nitrogênio.

Ao analisar a transição da agricultura baseada na fertilização orgânica para a química, em Portugal, Carmo et al. (2017) estimaram o balanço de nutrientes, utilizando os fertilizantes inorgânicos, a concentração de nutrientes na água da chuva e a sua precipitação, o processo de intemperismo do solo, a retirada de nutrientes por árvores e ervas daninhas e as perdas por lixiviação, erosão e emissão de $\mathrm{N}$ em estado gasoso. MacDonald et al. (2011) estimaram o balanço de fósforo no mundo, para o ano 2000, utilizando a aplicação de fertilizantes fosfatados e o esterco bovino como fontes de entrada de $P$, além da extração do nutriente por meio da absorção realizada pelas principais culturas.

No Brasil, os trabalhos desenvolvidos utilizaram o método do Balanço de Nutrientes do Solo (BNS). Esse método consiste na estimação dos fluxos de saída e de entrada de nutrientes no solo e a posterior subtração. O saldo negativo revela a redução da fertilidade do solo e o positivo, a existência de excedente. Saldos positivos foram encontrados por Yamada \& Lopes (1998) ao calcularam o balanço para 15 culturas durante os anos de 1993 e 1996. Cunha et al. (2018, 2010, 2011) também encontraram saldos negativos ao contabilizarem o balanço de nutrientes para o ano de 2008, para o período de 1988 a 2010 e de 2013 a 2016, respectivamente. Ao mensurar o BNS para os seis estados maiores produtores agrícolas do país, em 2005 e 2015, Azevedo Junior \& Rodrigues (2020) identificaram saldo positivo de Nitrogênio, Fósforo e Potássio para 
todos os estados nos dois anos, à exceção do Potássio no Paraná em 2015. Cunha et al. (2014) encontraram déficit nutricional somente quanto ao Molibdênio (Mo).

O SCEA recomenda a utilização do Balanço de Nutrientes do Solo (BNS). Existiriam três fluxos principais, a entrada de nutrientes por meio da aplicação de fertilizantes orgânicos e inorgânicos, a entrada via insumos orgânicos próprios das unidades produtivas, como a ciclagem de nutrientes e o uso de estrume, além da absorção de nutrientes pelo cultivo (Organização das Nações Unidas, 2014). A literatura registra, com maior frequência, as variáveis presentes na Tabela 3.

Tabela 3 - Registro na literatura das variáveis usadas neste trabalho.

\begin{tabular}{|c|c|c|c|c|}
\hline \multirow{2}{*}{ Autores } & \multicolumn{3}{|c|}{ Entrada } & Saída \\
\hline & $\mathrm{FBN}^{1}$ & Fertilizantes & Fertirrigação & Absorção \\
\hline
\end{tabular}

\section{Internacionais}

Sheldrick, Syers e Lingard (2003)

Vitousek et al. (2009)

MacDonald et al. (2011)

Carmo et al. (2017)

Chen, Sun e Shindo (2016)

\section{Nacionais}

Yamada e Lopes (1998)

Cunha et al. (2010)

Cunha et al. (2011)

Cunha et al. (2014)

Cunha et al. (2018)

Azevedo Junior e Rodrigues (2020)

$\checkmark$
$\checkmark$
$x$
$\checkmark$
$\checkmark$

$\checkmark$
$\checkmark$
$\checkmark$
$\checkmark$
$\checkmark$

$\begin{array}{ll}x & \checkmark \\ x & \checkmark \\ x & \checkmark \\ x & \checkmark \\ \checkmark & \checkmark\end{array}$

${ }^{1} \mathrm{FBN}=$ Fixação Biológica de Nitrogênio; $\checkmark$ - presente; $X$ - ausente.

Fonte: Adaptado de Azevedo Junior \& Rodrigues (2020).

A obtenção de dados relativos a cada uma dessas variáveis permite a construção do Balanço Nacional Físico de nutrientes para o Brasil em 2010, entretanto, para que essa informação conste na MCSA, faz-se necessária a sua monetização. Trata-se de um procedimento simples, em que o preço do fertilizante é multiplicado pela quantidade de nutriente exportada do solo ou nele introduzida. Ter-se-á o valor, em reais, do total investido ou recuperado por meio da introdução de nutrientes e a depleção ocorrida no ano. $O$ detalhamento desse procedimento é apresentado na seção a seguir.

\section{Materiais e Métodos}

O Produto Interno Bruto Ambiental (PIBA) foi calculado para o Brasil em 2010, por meio de uma Matriz de Contabilidade Social Ambiental. O recurso natural contemplado é o solo agrícola brasileiro, nos primeiros $20 \mathrm{~cm}$ do perfil do solo. A absorção de nutrientes ocorre somente nessa faixa de solo, de modo que os fluxos de nutrientes que interessam à fertilidade também se concentram nessa camada. Os fluxos foram estimados por meio do Balanço Físico de Nutrientes construído a partir dos fluxos de entrada e saída de Nitrogênio (N), Fósforo (P) e Potássio (K), para as 13 culturas que mais demandaram fertilizantes em 2010. A partir desse Balanço, temos o Saldo Físico de Nutrientes do Solo (SFNS). Os fluxos e o saldo físico, são inputs para a mensuração do Saldo Monetário de Nutrientes do Solo (SMNS) utilizado na MCSA. A apresentação dos métodos utilizados foi fragmentada em 3 subseções. A primeira 
dispõe a MCSA, a segunda e a terceira apresentam os balanços físico e monetário para o solo Brasileiro em 2010.

\subsection{A Matriz de contabilidade social ambiental (MCSA)}

A MCSA foi elaborada com 12 setores a partir das informações disponíveis no SCN (Instituto Brasileiro de Geografia e Estatística, 2016c) e na MIP (Instituto Brasileiro de Geografia e Estatística, 2016a) produzidas para o ano de 2010. A MIP é divulgada pelo IBGE por meio de 12 tabelas em que são apresentados todos os dados utilizados para a sua confecção. Este trabalho fez uso da "Oferta e demanda da produção nacional a preço básico", para extrair os dados relativos às transações realizadas entre os setores. Os valores dos impostos líquidos de subsídios e a da importação foram obtidos por meio da "Recursos de bens e serviços", enquanto que a exportação foi retirada da "Usos de bens e serviços". Os valores concernentes aos componentes do valor adicionado foram extraídos da "Tabela 17 Conta de produção e geração da renda, por setor institucional, segundo grupos de atividades - 2010-2015" do SCN. A "Principais agregados macroeconômicos das Contas Nacionais, por setor institucional" forneceu os valores do salário, excedente operacional bruto, rendimento misto e a formação bruta de capital fixo, por setores institucionais.

A partir destes dados, inicia-se a construção da MCSA organizada conforme a Tabela 1. Embora a utilização da MIP forneça dados equilibrados, a inclusão dos setores institucionais exige uma etapa de Equilíbrio de Recursos e Usos. Este equilíbrio depende da igualdade entre a oferta a preços de consumidor por produto e a demanda intermediária e final por esses produtos, considerando tanto os componentes do valor adicionado quanto os setores institucionais. A partir das diferenças encontradas entre a oferta e a demanda de cada produto, ajustes foram feitos para que as identidades contábeis presentes no SCN fossem respeitadas. Os salários e os lucros são apresentados, de foma agregada, como os valores apropriados pelas famílias e empresas, respectivamente. As variáveis, impostos e exportação, são consideradas exógenas ao modelo.

A etapa a seguir refere-se à inclusão dos dados ambientais que completam a estimação. Os dados sobre o solo foram obtidos por meio do BFNS. A Tabela 1 detalha a estrutura utilizada, especificando a introdução das variáveis Formação Bruta de Capital Natural Fixo do Solo (FBCNF solo) e a Depleção química do solo (D solo) presente no bloco do Valor Adicionado. $O$ fechamento da matriz foi realizado conforme procedimento adotado na etapa anterior e que está detalhado em Santana $(2005,1994)$.

Após a construção da matriz, pode-se estimar o PIBA de duas formas distintas: adicionando os dispêndios, com a introdução de nutrientes no solo e subtraindo a depleção do solo, que resultará no SMNS, como na Equação 9; utilizando a equação da demanda agregada keynesiana como em (Equação 10).

$P I B A=P I B+S M N S$

$P I B A=C F+C G+F B C F+S M N S+V E+(E-I m$.

Em que:

PIBA é o Produto Interno Bruto Ajustado Ambientalmente;

PIB é o Produto Interno Bruto;

SMNS é o Saldo Monetário de nutrientes do solo; 
CF é o Consumo das Famílias;

CG é o Consumo do Governo;

FBCF é a Formação Bruta de Capital Fixo;

VE é a Variação de Estoque;

E é o total das Exportações de bens e serviços;

Im. é a Importação total de bens e serviços.

Conforme proposto no início da pesquisa, além do PIBA, mensuramos os indicadores de efeitos de transferência, que se referem às relações entre os setores produtivos da economia: o circular, que se resume nas interações entre os blocos dos setores com o do valor adicionado, revelando o dispêndio com a aquisição de insumo; o cruzado, relacionado ao efeito de transbordamento, que se origina das atividades produtivas ao gerarem o valor adicionado que é apropriado pelo governo e famílias (instituições); e o global, com o objetivo de identificar os impactos do aumento da produção dos setores da economia sobre a fertilidade do solo (Santana, 2005)

Ao mensurarmos o efeito de transferência (MET), teremos a estimativa de depleção do solo agrícola, em reais, gerada pelo incremento de $\mathrm{R} \$ 1$ na demanda por produtos agropecuários. O efeito circular (MEC) e o efeito cruzado (MECZ) revelarão a magnitude de $D$ solo quando a demanda por produtos de outros setores aumentar e, por transbordamento, elevando a demanda por produtos agropecuários. Os efeitos globais $(\mathrm{Mg})$ revelam a magnitude do impacto da soma dos três efeitos sobre a exaustão do solo. A mesma análise deve ser feita para os investimentos no solo. A elevação da demanda por produtos agropecuários (MET) de outros setores (MEC e MECZ) deve vir acompanhada de FBCNFsolo como garantia de produtividade.

\subsection{Balanço físico de nutrientes do solo (BFNS).}

A estimativa da quantidade total de nutrientes exportados em solos agrícolas, no Brasil, foi realizada por meio da somatória da multiplicação do teor médio do nutriente presente na porção comercial de determinada cultura pela quantidade total de produtos colhidos conforme Azevedo Junior (2019), por ano, como em (Equação 11):

$X s_{i}=\Sigma\left(T x c^{*} Q c_{i}\right)$

Em que:

$X_{s_{i}}$ é a quantidade do nutriente X exportado anualmente por todas as culturas consideradas no ano i.

$T x c$ é o teor do nutriente $\mathrm{X}$ exportado pela cultura c.

$Q c_{i}$ é a quantidade produzida da cultura c no ano i.

A quantidade produzida se refere aos 13 cultivos que, conforme Associação Nacional para Difusão de Adubos (2011), mais demandaram fertilizantes em 2010: soja, milho, algodão, tomate, feijão, cana-de-açúcar, café, trigo, arroz, fumo, batata, laranja e banana. Os dados relativos à produção foram obtidos por meio da Pesquisa Agrícola Municipal (PAM). Os teores médios de nutrientes exportados, por cultura, foram selecionados na literatura científica nacional e são apresentados na Tabela 4, que dispõe a quantidade média, expressa em quilogramas, de Nitrogênio, Fósforo e Potássio, exportada, por tonelada produzida de cada cultura.

Embora seja encontrado em abundância na atmosfera, a maior parte do $\mathrm{N}$ aportado ao solo ocorre por meio de fixação biológica (Fernandes, 2006). As culturas oleaginosas são as principais responsáveis por esta fixação (Cunha et al., 2014). Em alguns casos, pode-se observar a existência de saldo positivo de $\mathrm{N}$ no solo, no pós-safra, e sua disponibilidade para a safra 
Tabela 4 - Quantidade Média Anual de Nutrientes Exportados pelas Culturas consideradas neste trabalho.

\begin{tabular}{crrr} 
& $\mathbf{N}$ & $\mathbf{P}$ & $\mathbf{K}$ \\
\cline { 2 - 4 } Cultivo & & $\mathbf{k g} / \mathbf{t}$ & 20,00 \\
Soja & 51,00 & 10,00 & 14,36 \\
Milho & 21,22 & 4,19 & 0,96 \\
Cana-de-açúcar & 0,47 & 0,08 & 19,60 \\
Café & 23,90 & 1,30 & 18,40 \\
Algodão & 28,40 & 7,40 & 5,00 \\
Trigo & 30,30 & 4,41 & 4,40 \\
Arroz & 12,50 & 2,20 & 9,52 \\
Feijão Caupi & 29,00 & 2,92 & 15,30 \\
Feijão Comum & 35,50 & 4,00 & 36,00 \\
Fumo & 29,00 & 2,00 & 5,35 \\
Batata & 2,00 & 0,40 & 1,76 \\
Laranja & 1,96 & 0,44 & 15,56 \\
Banana & 3,78 & 0,58 & 3,48 \\
Tomate & 2,00 & 0,30 &
\end{tabular}

N é o Nitrogênio, P é o Fósforo e K é o Potássio. ${ }^{1}$ em quilogramas de nutrientes por tonelada de produto produzido. Fonte: Azevedo Junior (2019).

seguinte (Rodrigues Alves et al., 2006). No Brasil, a área colhida destinada para a soja, o milho e o feijão, culturas oleaginosas, alcançou 61\% em 2010 (Instituto Brasileiro de Geografia e Estatística, 2016b).

Neste estudo, assumiu-se que $100 \%^{2}$ do nitrogênio absorvido pela soja (SBCS, 2004; Sfredo, 2008) entrou no solo devido à Fixação Biológica realizada pelo próprio cultivo, que ocupou $36 \%$ da área colhida no Brasil, em 2010. O excedente de N fixado pela soja é absorvido pelo milho de segunda safra, cultivado, estrategicamente, após a colheita da soja. Considera-se que $74 \%{ }^{3}$ (Gitti, 2013) da exportação de nitrogênio absorvida pelo milho safrinha se deve à FBN da soja e não à introdução de fertilizantes.

A absorção de nitrogênio oriundo da FBN também ocorre na produção do feijão. Estima-se que $75,74 \%$ do $\mathrm{N}$ absorvido, em média ${ }^{4}$, pelo feijão-caupi (Vigna unguiculata (L.) WALP.) se origine da Fixação Biológica, enquanto $55,45 \%$ do $\mathrm{N}$ absorvido, em média, pelo feijão-comum (Phaseolus vulgaris L.), tenha a mesma origem (Brito et al., 2009). No entanto, como afirmam Filho et al. (2011), os levantamentos oficiais, realizados pelo IBGE, referem-se à somatória do feijão-caupi e do feijão-comum.

Filho et al. (2011) estimam que, entre 2005 e 2009, a média anual de participação do feijão-caupi na produção total de feijão seria de $15,48 \%$, tendo o feijão-comum ocupado a

2 Tem-se certa unanimidade quanto à autossuficiência da soja em relação à absorção de nitrogênio, no entanto, alguns autores como Lamera et al. (2006) e Lamond \& Wesley (2001), entre outros defendem que a aplicação de fertilizantes nitrogenados pode elevar a produtividade da soja ao se aproveitar a marcha de absorção da planta. Optou-se, neste trabalho, por considerar a autossuficiência devido à maior aceitação presente na literatura.

${ }^{3}$ A FBN pela soja deixa um residual de 35 a $45 \mathrm{~kg}$ de $\mathrm{N}$ por ha que a mineralização libera, em média, $20 \mathrm{~kg}$ de $\mathrm{N}$ para cada $1 \%$ de MOS. Sabendo que os solos agricultáveis possuem $3 \%$ de MOS, tem-se a liberação de $60 \mathrm{~kg}$ de N por ha. Desse modo, solos agrícolas podem fornecer cerca de $100 \mathrm{~kg}$ de $\mathrm{N}$ por ha para a cultura do milho em sucessão à soja (Gitti, 2013). Segundo a CONAB (Brasil, 2016), o milho de segunda safra possui média de 95,3 sacas por hectare, produtividade que leva à extração de cerca de média de $135 \mathrm{~kg}$ de N por ha (Gitti, 2013). Como $100 \mathrm{~kg}$ adentram ao solo via FBN, tem-se que $74 \%$ do $\mathrm{N}$ exportado de origem da FBN é realizada pela soja.

${ }^{4}$ A média foi calculada a partir da participação da FBN no desenvolvimento das duas variedades de feijão em quatro períodos diferentes, 17, 31, 58 e 78 dias após a semeadura, utilizando o Método da Diferença (Brito et al., 2009). 
participação restante. Pode-se extrapolar esses percentuais para os demais anos a fim de detalhar a produção de cada variedade. Multiplicando essa quantidade pelo teor médio de $\mathrm{N}$ presente no feijão colhido, encontra-se o total exportado para cada variedade. A quantidade referente à FBN é encontrada por meio da multiplicação do total de nitrogênio exportado, por variedade, pela estimativa apresentada no início deste parágrafo.

Segundo De Resende et al. (2006) e Oliveira et al. (2010), a vinhaça, um subproduto do beneficiamento da cana-de-açúcar, possui significativa concentração de nutrientes, dentre os quais se destaca o K. Assim como Cunha et al. (2014), adotou-se que o percentual de que 50\% do K exportado por essa cultura se origina da aplicação da vinhaça.

O consumo agregado de fertilizantes no Brasil é calculado e disponibilizado, anualmente, pela Associação Nacional para Difusão de Adubos. Como as 13 culturas consideradas contemplam cerca de $90,72 \%$ da totalidade dos fertilizantes entregues em 2015, torna-se necessária a dedução dos fertilizantes entregues para uso em outras culturas e que, por isso, não são considerados neste trabalho, conforme (Equação 5). Adotou-se o percentual de 2015 como referência para os demais anos (Equação 12).

$F c_{i}=F t_{i} * 9,28 \%$

Em que:

$F c_{i}=$ é a quantidade de fertilizantes entregues às 13 culturas consideradas na análise.

$F t_{i}=$ é a quantidade total de fertilizantes entregues no Brasil.

A quantidade de nutrientes será calculada multiplicando o percentual anual médio de concentração de cada nutriente, no produto final, pela quantidade de fertilizantes entregues para as 13 culturas. Conforme (Equação 13).

$Q X_{i}=F c_{i} * \overline{C X}_{i}$

Em que:

$Q X_{i}=$ é a quantidade do nutriente $\mathrm{X}$ entregue no ano i.

$\overline{C X}_{i}=$ é o percentual anual médio de concentração de cada nutriente nos fertilizantes.

A totalidade de nutrientes adicionados ao solo resulta da soma da FBN com os fertilizantes nitrogenados, para o nitrogênio (Equação 14), do uso da vinhaça e aplicação de fertilizantes potássicos, para o potássio (Equação 15) e do total de fertilizantes fosfatados, para o fosfato (Equação 16).

$$
\begin{aligned}
& N e_{i}=F B N_{i}+Q N_{i} \\
& K e_{i}=V_{i}+Q K_{i} \\
& P e_{i}=Q P_{i}
\end{aligned}
$$

Em que:

$Q N_{i}, Q K_{i} e Q P_{i}$ são as quantidades de $\mathrm{N}, \mathrm{K}$ e $\mathrm{P}$ entregues no ano i;

$\mathrm{FBN}_{\mathrm{i}}$ é a quantidade de $\mathrm{N}$ fixada biologicamente pelas culturas da soja, do milho e do feijão, no ano i;

V é a quantidade de $\mathrm{K}$ introduzido no solo pela fertirrigação da cana-de-açúcar com a vinhaça, no ano i. 
O fluxo de saída de nutrientes é dado pela Equação 11, enquanto os fluxos de entrada são mensurados nas Equações 14, 15, 16. Pode-se agora, mensurar o SMNS como explicitado nas Equações 17, 18, 19.

$$
\begin{aligned}
& S N_{i}=N e_{i}-N s_{i} \\
& S K_{i}=K e_{i}-K s_{i} \\
& S P_{i}=P e_{i}-P s_{i}
\end{aligned}
$$

Em que:

$S N_{i}, S K_{i} e S P_{i}=$ saldo de Nitrogênio, Potássio e Fósforo, respectivamente, em solo brasileiro, no ano i. $N e_{i}, K e_{i}, P e_{i}=$ total de Nitrogênio, Potássio e Fósforo, respectivamente, introduzidos em solo brasileiro no ano i.

$N s_{i}, K s_{i} e P s_{i}=$ total de Nitrogênio, Potássio e Fósforo, respectivamente, exportados do solo brasileiro, no ano i.

A partir dos dados físicos, pode-se estimar o SMNS, como descrito na subseção a seguir.

\subsection{Balanço monetário de nutrientes do solo (BMNS)}

O saldo de nutrientes permite, portanto, mensurar, monetariamente, o valor da depreciação do solo, por meio do dispêndio com a aquisição de fertilizantes inorgânicos responsáveis por recuperar a fertilidade do solo, garantindo sua máxima eficiência. A variável preço se baseia no Superfosfato simples (SSP), para o saldo do fosfato, na Ureia, para o nitrogênio, além do Cloreto de Potássio para o saldo de potássio. Conforme ANDA (2016), esses fertilizantes entregaram a maior parte dos nutrientes utilizados pela agricultura nacional em 2015. Os preços dos fertilizantes foram disponibilizados pelo Instituto de Economia Aplicada da Secretaria de Agricultura e Abastecimento do Estado de São Paulo (IEA/SAA-ESP). O Saldo Monetário de Nutrientes do Solo é calculado conforme a Equação 20.

SMNS $_{i}=$ FBCNFm solo $i-$ Dm solo $_{i}$

Em que:

$S M N S_{i}$ é o saldo monetário de nutrientes do solo, no ano i.

FBCNFm solo é a formação bruta de capital natural fixo monetário do solo.

Dm solo é a depleção monetária do solo.

O saldo será incluído na MCSA por meio da inserção da FBCNF msolo no bloco da Demanda Final, assim como a FBCF e da inserção de D msolo no bloco do Valor Adicionado.

A quantidade dos nutrientes, que é extraída do solo pelo cultivo, revela a magnitude física de sua exaustão, conforme a Equação 21, que deve ser monetizada para a sua inclusão no cálculo do PIBA.

$\operatorname{Dsolo}_{i}=N s_{i}+P s_{i}+K s_{i}$

Em que:

$D$ solo $o_{i}$ é a depleção do solo agrícola no ano i, em toneladas. 
$N s_{i}, K s_{i} e P s_{i}$ representam o total de Nitrogênio, Potássio e Fósforo, respectivamente, exportados do solo brasileiro, no ano i em toneladas.

A absorção total de cada nutriente é mensurada por meio da somatória da multiplicação do teor médio do nutriente presente na tonelada colhida de determinada cultura no Brasil, pela quantidade total de produtos colhidos, por ano, como na Equação 11. Por outro lado, o aumento de sua fertilidade se daria em decorrência da entrada de N, P e K, via aplicação de fertilizantes inorgânicos, fixação biológica e fertirrigação com vinhaça. A quantidade destes nutrientes que adentra ao solo, devido às práticas de manejo citadas, revela a magnitude da oferta de nutrientes, conforme a Equação 22.

$F B C N F$ solo $_{i}=N e_{i}+P e_{i}+K_{i}$

Em que:

FBCNFsolo ${ }_{i}$ é a Formação Bruta de Capital Natural Fixo do Solo no ano i em toneladas.

$N e_{i}, K e_{i}, P e_{i}$ total de Nitrogênio, Potássio e Fósforo, respectivamente, introduzidos em solo brasileiro no ano i.

O saldo obtido por meio da subtração da entrada pela saída de nutrientes é calculado na Equação 23. Um resultado negativo indica que a entrada total não foi suficiente para repor a depleção causada pelo cultivo e, de modo oposto, um resultado positivo indica que a entrada total de N, P e K devolveu a fertilidade do solo e adicionou mais nutrientes. Embora não incorra em uma depleção nutritiva, a positividade do saldo de nutrientes pode gerar externalidades negativas associadas à eutrofização (Vitousek et al., 2009) e à desertificação (Manzatto et al., 2002) e ao aumento dos custos internos de produção, tendo em vista que o aumento da concentração de alguns nutrientes pode causar a inibição da absorção de outros (Meurer, 2006). O excesso pode ser considerado um passivo ambiental. A nulidade revela que o balanço físico da quantidade de macronutrientes foi equilibrado, sem a presença de externalidades negativas, sendo este o resultado ideal.

SFNS $_{i}=F B C N F$ solo $_{i}-$ Dfsolo $_{i}$

Em que:

$S F N S_{i}$ é o Saldo Físico de Nutrientes do Solo no ano i.

A monetização da exaustão nutritiva do solo após a colheita é realizada por meio da multiplicação da depreciação física ( $D$ solo ) e da aplicação de fertilizantes ( $F B C N F$ solo ), pelo preço de mercado dos principais fertilizantes utilizados para a reposição de cada um dos nutrientes, conforme as Equações 24, 25.

Dmsolo $_{i}=\mathrm{Pfe}_{i} * \mathrm{Dfsolo}_{i}$

FBCNFmsolo $_{i}=$ Pfe $_{i} *$ FBCNFfsolo $_{i}$

Em que:

$D m s o l o_{i}$ é a depleção monetária do solo no ano i.

FBCNFm solo ${ }_{i}$ é o total monetário dispendido para a aplicação de nutrientes no solo no ano i.

$P f e_{i}$ é o preço médio do fertilizante inorgânico no ano i. 


\section{Resultados}

O solo agrícola foi utilizado para ajustar o valor do PIB. A partir do Balanço de Nutrientes, foi possível identificar o total de N, P e K extraídos do solo nacional em função do cultivo agrícola das treze culturas consideradas e o total introduzido via fertilização, fertirrigação e fixação biológica. Na Tabela 5, apresenta-se o resultado desta conta, que revelou um saldo positivo para os três nutrientes. Quanto à soma de N, P e K, o solo foi depreciado em R $\$ 11.687$ milhões, mas obteve aporte de $\mathrm{R} \$ 15.833$ milhões, o suficiente para recuperar a depleção mensurada e garantir um excedente de $\mathrm{R} \$ 4.146$ milhões. Em outras palavras, do total empregado na forma de FBCNF solo, R\$11.687 milhões, na verdade, se referem à reposição da fertilidade do ativo imobilizado, sem incrementar um valor novo à economia. O excedente, entretanto, pode ser entendido como um valor incremental à medida que representa um dispêndio realizado para a introdução de mais nutrientes a fim de ampliar a fertilidade do solo.

Tabela 5 - Saldo de Nutrientes no Solo Agrícola Brasileiro, 2010.

\begin{tabular}{|c|c|c|c|c|c|c|c|}
\hline \multirow[b]{2}{*}{ Nutrientes } & \multicolumn{3}{|c|}{ Físico ${ }^{1}$} & \multirow[b]{2}{*}{ Preço RS } & \multicolumn{3}{|c|}{ Monetário ${ }^{2}$} \\
\hline & $\begin{array}{l}\text { FBCNF } \\
\text { Solo }\end{array}$ & D solo & Saldo & & $\begin{array}{c}\text { FBCNF } \\
\text { Solo }\end{array}$ & D solo & Saldo \\
\hline $\mathrm{N}$ & 6.717 .867 & 5.709 .028 & 1.008 .840 & 1.320 & 8.869 & 7.537 & 1.332 \\
\hline $\mathrm{P}$ & 3.072 .593 & 1.083 .171 & 1.989 .421 & 676 & 2.007 & 732 & 1.345 \\
\hline K & 3.879 .436 & 3.298 .529 & 580.906 & 1.459 & 5.659 & 4.811 & 847 \\
\hline $\mathrm{N}, \mathrm{P}$ e K & 13.669 .896 & 10.090 .728 & 3.579 .167 & 1.158 & 15.833 & 11.687 & 4.146 \\
\hline
\end{tabular}

${ }^{1} \mathrm{Em}$ toneladas. ${ }^{2} \mathrm{Em}$ um milhão de reais deflacionados para 2010. N é o nitrogênio. $P$ é o fósforo. K é o potássio. FBCNF Solo é a Formação Bruta de Capital Natural Fixo do solo. D solo é a depreciação do capital natural do solo. Preço é a média anual dos preços dos fertilizantes Superfosfato simples (P), Ureia (N) e Cloreto de Potássio (K), em reais por tonelada.

Fonte: Elaborado pelos autores.

Esse resultado confirma as conclusões apresentadas em Cunha et al. (2018, 2010, 2011), que também encontraram o saldo positivo em suas estimações físicas do Balanço de Nutrientes. 0 saldo positivo também foi encontrado por Azevedo Junior \& Rodrigues (2020) em R\$61.592,99, em 2005, e R\$146.271,01, em 2015, para os estados de MT, PR, RS, SP, MG e GO.

$\mathrm{O}$ excedente encontrado pode se tornar um passivo ambiental, à medida que ultrapassa a quantidade de sítios de cargas nos coloides, aumentando a concentração de N, P e K na solução, podendo produzir graves externalidades. $\mathrm{O}$ excesso de $\mathrm{N}$ e de $\mathrm{P}$ é apontado por Vitousek et al. (2009) como o motivo da eutrofização ocorrida no Golfo do México, e o mesmo fenômeno foi observado no Espírito Santo $(G 1,2016)$ e em São Paulo $(G 1,2018)$. O saldo positivo de $\mathrm{KCl}$ pode levar à desertificação (Manzatto et al., 2002). Além disso, as emissões atmosféricas de óxido nitroso também são apontadas como resultantes do excesso de $\mathrm{N}$ no solo (Organização das Nações Unidas, 2014). Portanto, ainda que o resultado do saldo monetário de nutrientes do solo tenha retornado um valor positivo, não se deve considerá-lo como um investimento em variação de estoque. Isso só seria possível se pudéssemos estimar a capacidade de suporte do solo brasileiro e, assim, estabelecer o total de nutrientes que podem ser introduzidos sem exceder o total de sítios de carga disponíveis. Como essa estimação é complexa, demandando, inclusive, análise de campo, esse valor excedente deve ser considerado um custo associado às externalidades negativas que produz ao não permanecer no solo. $O$ saldo, portanto, deve ser descontado do PIB, como revela a Tabela 6 que dispõe o PIBA, calculado conforme as Equações 9, 10, em que o saldo monetário de nutrientes do solo é considerado. 
Tabela 6. Produto Interno Bruto Ajustado pela Depreciação do Solo Agrícola Brasileiro em 2010.

\begin{tabular}{ccccc}
\multicolumn{2}{c}{ Brasil } & & \multicolumn{2}{c}{ Setor agropecuário } \\
\hline Conta & Milhões de R\$ & & Conta & Milhões de R\$ \\
Consumo do governo & 798.182 & & Salário & 37.026 \\
Consumo das Famílias & 1.918 .538 & & Lucro & 122.906 \\
FBCF & 704.389 & & Impostos & 7.072 \\
Exportação & 422.176 & & PIB agro & 167.004 \\
Importação & $(-) 797.894$ & & FBCF Solo & 15.833 \\
Variação de estoque & 840.456 & & D solo & $(-) 11.687$ \\
PIB & 3.885 .847 & SMNS & 4.146 \\
FBCF Solo & 15.833 & & & \\
D solo & $(-) 11.687$ & & & $162.858^{1}$ \\
SMNS & 4.146 & PIBA & \\
PIBA & $3.881 .701^{1}$ & & & \\
\hline
\end{tabular}

FBCNF Solo é a Formação Bruta de Capital Natural Fixo do solo. D solo é a depreciação do capital natural do solo. ${ }^{1} \mathrm{O}$ Saldo Monetário de nutrientes do solo (SMNS) positivo indica a ocorrência de custos de produção associados à perda de nutrientes, por este motivo, esse saldo é descontado do PIB.

Fonte: Elaborado pelos autores, a partir de dados do (Instituto Brasileiro de Geografia e Estatística, 2016a)

A depleção causada pela produção agrícola representou um deságio de 0,30\%, na produção nacional, e de 7\%, na produção do setor agropecuário, montante recuperado por meio de dispêndios direcionados à reposição de N, P e K em 0,41\% e 9,5\% do PIB nacional e do PIB agropecuário, respectivamente. O saldo positivo do Balanço de nutrientes significou potencial externalidade de 0,11\% do total gerado no Brasil em 2010 e de 2,42\% da riqueza gerada pelo setor agropecuário. A FBCNF solo foi $46 \%$ superior ao montante dedicado à FBCF deste setor.

O PIBA brasileiro seria, portanto, R\$3.881 bilhões e o PIBA agropecuário, de R $\$ 162$ bilhões. Este resultado vai de encontro à conclusão alcançada por Brasileiro (2012) que estimou um PIBA da Amazônia legal 15\% menor em relação ao PIB em 2012. Na Colômbia, Maldonado \& Lachaud (2011) concluíram pela sobrevalorização da taxa de crescimento do PIB em 0,9\%, ao considerarem o esgotamento do gás natural e a poluição do ar por gás carbônico, como fatores de ajustes ambientais. Ao considerar os recursos florestais, Haripriya (2001) registrou uma redução de 1,6\% do produto interno indiano, enquanto Gundimeda et al. (2007) encontraram uma diferença de $1 \%$.

Em que pese a similaridade dos resultados encontrados na literatura enfatizar que a superestimação realizada pelo PIB, em comparação ao PIBA no caso do solo brasileiro, não se deve à existência de uma depleção nutritiva do capital natural, como observado nos trabalhos citados. A busca pela manutenção da fertilidade do solo, em relação à safra imediatamente anterior, tem levado os produtores a aplicarem fertilizantes em quantidades superiores àquelas retiradas pelo cultivo. O montante investido e que excede o total extraído pela planta, portanto, se transforma em um custo.

A Tabela 6 foi construída por meio dos dados da MCSA de 2010. Essa matriz também permite a construção de indicadores por meio dos quais é possível mensurar em quanto a fertilidade do solo será comprometida a cada incremento na demanda exógena e, também, o montante que deverá ser investido em sua recuperação.

Além da transferência da agropecuária para os demais setores, do estímulo provocado pelo aumento da demanda exógena, foi possível estimar os efeitos de transbordamento gerados pela agropecuária e apropriados pelas instituições. Esses efeitos são captados pela matriz de efeitos cruzados e apresentam o aumento do valor adicionado e do consumo endógeno, conforme a Tabela 7. A cada aumento de R\$1 milhão na demanda final exógena da atividade 
agropecuária, ter-se-ia dispêndios em nutrição do solo ampliados em $\mathrm{R} \$ 5.735,46$, cerca de $13 \%$ da FBCF de máquinas e equipamentos e que supera a depleção nutritiva do solo em $26 \%$.

Tabela 7. Efeitos cruzados da agropecuária brasileira em 2010.

\begin{tabular}{rr} 
Instituições & $289.139,01$ \\
Consumo do Governo & $338.001,80$ \\
Consumo das famílias & $43.970,26$ \\
Formação Bruta de Capital Fixo & $5.735,46$ \\
\hline Formação Bruta de Capital Fixo do solo agrícola & $244.737,69$ \\
Contas & $596.225,19$ \\
Salários & $(-) 4.233,58$ \\
\hline
\end{tabular}

Fonte: Elaborado pelo autor.

Além de ampliar a produção de toda a economia e de aumentar o valor adicionado que é apropriado e consumido pelas instituições, o aumento da produção agropecuária, provocado pelo incremento de $\mathrm{R} \$ 1$ milhão na demanda exógena, pode provocar um segundo aumento na demanda por produtos agropecuários; esse é o efeito circular. Esse efeito é apresentado na Tabela 8 e revela que, além dos $R \$ 69$ mil correspondentes ao efeito de transferência, a agropecuária incrementa sua produção em $R \$ 114,8$ mil a cada $R \$ 1$ milhão de reais ampliados da demanda exógena por seus produtos. Esse mesmo real provocaria um aumento de $R \$ 892,6$ mil na produção da indústria de transformação, $\mathrm{R} \$ 614,5$ mil na oferta de outros serviços, $\mathrm{R} \$ 646,7$ mil na oferta de administração pública, saúde, educação e seguridade social, além de $\mathrm{R} \$ 366,2$ mil na oferta de produtos relacionados ao comércio. Essas 5 atividades correspondem a $36 \%$ de todo o efeito circular provocado pelo aumento das exportações da agropecuária.

Tabela 8 - Efeito Circular da Agropecuária Brasileira em 2010.

\begin{tabular}{cr} 
Setores & $892.627,50$ \\
Indústria de transformação & $646.741,78$ \\
Administração, saúde e educação públicas e seguridade social & $614.512,81$ \\
Outros serviços & $366.272,30$ \\
Comércio & $114.810,67$ \\
Agropecuária & $1.059 .481,33$ \\
Outros setores & $445.779,29$ \\
Instituições & $1.188 .988,61$ \\
Consumo do Governo & $67.791,03$ \\
Consumo das famílias & $8.842,62$ \\
Formação Bruta de Capital Fixo & $1.045 .198,93$ \\
Formação Bruta de Capital Fixo do solo agrícola & $919.228,58$ \\
Contas & $(-) 6.527,11$ \\
Salários & Lucros \\
\hline
\end{tabular}

Fonte: Elaborado pelo autor.

O efeito circular permite ainda constatar o impacto sobre a FBCNF solo. Seria exigido um total de $\mathrm{R} \$ 8.842,62$ para cada um milhão efetivamente elevado da demanda exógena, para 
a manutenção da fertilidade do solo, em resposta à ampliação em um milhão de reais da demanda e uma depleção de $\mathrm{R} \$ 6.527,11$, apenas para manter o equilíbrio físico do balanço de macronutrientes.

A matriz de multiplicadores globais é o resultado da soma dos efeitos de transferência, cruzado e circular, e revela todos os efeitos gerados, na economia, a partir da indução da atividade agropecuária por meio do aumento de $\mathrm{R} \$ 1$ milhão em sua demanda exógena. Esses efeitos globais são apresentados na Tabela 9 e sintetizam todos os efeitos diretos e indiretos, que surgem das interações setoriais, intersetoriais e com as instituições.

Tabela 9 - Multiplicador Global da Agropecuária Brasileira em 2010.

\begin{tabular}{cr} 
Setores & \\
Indústria de transformação & $1.200 .782,26$ \\
Agropecuária & $1.184 .410,84$ \\
Outros serviços & $650.167,08$ \\
Administração, saúde e educação públicas e seguridade social & $646.741,78$ \\
Comércio & $436.854,24$ \\
Outros setores & $1.210 .578,41$ \\
Instituições & \\
Consumo do Governo & $734.918,31$ \\
Consumo das famílias & $1.526 .990,41$ \\
Formação Bruta de Capital Fixo & $111.761,30$ \\
Formação Bruta de Capital Fixo do solo agrícola & $14.578,08$ \\
Contas & $1.289 .936,62$ \\
Salários & $1.515 .453,77$ \\
Lucros & $(-) 10.760,69$ \\
\hline
\end{tabular}

Fonte: Elaborado pelo autor.

O estímulo inicial, ocasionado pelo aumento da demanda exógena, provoca uma repercussão de $\mathrm{R} \$ 5.329$,5 mil na economia como um todo. O nível de produção nacional, portanto, mais que quadruplica a cada elevação em $\mathrm{R} \$ 1$ milhão das exportações de produtos da agropecuária. Este resultado confirma o potencial do campo como indutor do crescimento econômico brasileiro, principalmente quanto à interação vertical com a indústria de transformação, que engloba o agronegócio nacional. As repercussões econômicas da produção agropecuária também estimulam a demanda por serviços públicos, exigindo, em contrapartida, que os governos estaduais, municipais e federais ampliem a oferta em $\mathrm{R} \$ 646,7$ mil para cada aumento de $\mathrm{R} \$ 1$ milhão nas exportações agropecuárias.

Com efeito, o aumento da produção elevaria o valor adicionado para $\mathrm{R} \$ 2.805,3$ mil. Deste valor, cerca de $55 \%$ são apropriados pelas famílias e $5 \%$ seriam destinados para a formação bruta de capital fixo. No entanto, a indução da produção agropecuária, pelo aumento de um milhão de reais da exportação, possibilita o crescimento da produção ao custo da depreciação do capital natural brasileiro em $\mathrm{R} \$ 10.760,69$. Os dispêndios totais em FBCF solo totalizam $\mathrm{R} \$ 14.578,08$.

\section{Considerações finais}

Este trabalho calculou a Matriz de Contabilidade Social e Ambiental para quantificar o impacto da produção sobre o solo, aqui entendido como um ativo imobilizado para a produção 
agrícola. O Balanço de nutrientes do solo, por meio do qual foi possível estimar, em unidades monetárias, a depleção química do solo agrícola nacional quanto ao teor de N, P e K, além dos dispêndios relacionados à aplicação desses nutrientes via fertilizantes, fertirrigação e FBN. A partir desse exercício que adensou conhecimentos agronômicos e econômicos, percebeu-se que os dispêndios direcionados à recuperação da fertilidade do solo não são tão significantes no nível da produção nacional. Além disso, a depleção causada pela safra anual é totalmente reposta, no mesmo ano e produz um excedente.

As técnicas de manejo executadas pelo agronegócio brasileiro têm permitido o aumento da produtividade no campo sem acelerar o processo de esgotamento do solo. $\mathrm{O}$ excesso de $\mathrm{N}, \mathrm{Pe}$ $\mathrm{K}$, entretanto, deve ser ponderado com cuidado. Problemas gerados a partir desse excedente podem tornar a área imprópria para o cultivo e poluir as águas subterrâneas, atingindo lagos e rios, causando a morte de peixes. Nesse sentido, o saldo positivo encontrado foi subtraído do PIB. O PIBA apresentou um deságio de $0,11 \%$ e o PIBA da agropecuária, 2,5\%.

Esse resultado torna-se relevante devido à importância que a agricultura tem desempenhado na indução do crescimento econômico nacional, bem como na política de comércio exterior. Isso pode ser mais bem observado na medida em que o aumento da demanda por produtos agropecuários causada pela repercussão e um aumento da demanda dos demais setores da economia geram uma depleção do solo de $1 \%$.

As limitações do trabalho se referem ao fato de considerar, somente, a depleção do solo por meio dos fluxos de N, P e K, faltando outros nutrientes que, embora utilizados em menor quantidade, são relevantes para o desenvolvimento vegetal, além dos aspectos físicos e da solução do solo. Tem-se ainda as limitações impostas pelas hipóteses do modelo que não permitem que as inferências aqui alcançadas sejam aplicadas no longo prazo. Entretanto, a metodologia utilizada pode ser adaptada para, em trabalhos futuros, contemplar os fluxos de outros nutrientes, bem como a degradação da parte física e líquida do solo.

\section{Referências}

Alleoni, L. R. F., de Mello, J. W. V., \& Rocha, W. S. D. da R. (2016). Eletroquímica, Adsorção e troca iônica no solo. In L. R. F. Alleoni \& V. F. Melo (Eds.), Química e Mineralogia do Solo - Parte 2 (1. ed, pp. 70-123). Viçosa: Sociedade Brasileira de Ciência do Solo.

Andrade, J. C. (2016). Conceitos Básicos de Química. In L. R. F. Alleoni \& V. F. Melo (Eds.), Química e Mineralogia do solo - parte 2 (1. ed). Viçosa: Sociedade Brasileira de Ciência do Solo.

Associação Nacional para Difusão de Adubos - ANDA. (2011). Anuário Estatístico do Setor de Fertilizantes, 2010. São Paulo: ANDA.

Associação Nacional para Difusão de Adubos - ANDA. (2016). Anuário Estatístico do Setor de Fertilizantes, 2015. São Paulo: ANDA.

Azevedo Junior, W. C. (2019). Balanço de nutrientes e sua inclusão no produto interno bruto do Brasil ajustado pela depreciação do solo agrícola (Tese de doutorado). Universidade Federal do Pará, Belém.

Azevedo Junior, W. C., \& Rodrigues, M. (2020). Soil management in Brazilian states: comparative analyzes of Physical and Monetary Soil Nutrient Balance in 2005 and 2015. Revista Agro@ Mbiente, 14, 1-16. https://doi.org/10.18227/1982-8470ragro.v14i0.6193

Banerjee, O., Cicowiez, M., Vargas, R., \& Horridge, M. (2017). The SEEA-Based Integrated Economic-Environmental Modelling Framework: an illustration with Guatemala's forest 
and fuelwood sector. Environmental and Resource Economics, 72, 1-20. http://dx.doi. org/10.1007/s10640-017-0205-9

Brasil. Agência Nacional de Águas - ANA. Instituto Brasileiro de Geografia e Estatística - IBGE. (2018). Contas Econômicas Ambientais da Água no Brasil. IBGE, Coordenação de Contas Nacionais, Rio de Janeiro.

Brasil. Companhia Nacional de Abastecimento - Conab. (2016). Série Histórica de Produção Milho 1a e 2a safras. Série Histórica das Safras, Brasília.

Brasileiro, A. C. B. (2012). Produto interno bruto ajustado ambientalmente para Amazônia legal brasileira: uma análise de matriz de insumo-produto e matriz de contabilidade social (Dissertação de mestrado). Universidade de São Paulo, São Paulo.

Brito, M. M. P., Muraoka, T., \& Silva, E. C. (2009). Marcha de absorção do nitrogênio do solo, do fertilizante e da fixação simbiótica em Feijão-Caupi (Vigna unguiculata (L.) walp.) e Feijãocomum (Phaseolus vulgaris L.) determinada com uso de N. Revista Brasileira de Ciência do Solo, 33(4), 559-565. http://dx.doi.org/10.1590/S0100-06832006000200004

Carmo, M., García-Ruiz, R., Ferreira, M. I., \& Domingos, T. (2017). The N-P-K soil nutrient balance of Portuguese cropland in the 1950s: The transition from organic to chemical fertilization. Scientific Reports, 7(1), 1-14. http://dx.doi.org/10.1038/s41598-017-08118-3

Chen, M., Sun, F., \& Shindo, J. (2016). China's agricultural nitrogen flows in 2011: environmental assessment and management scenarios. Resources, Conservation and Recycling, 111, 1027. http://dx.doi.org/10.1016/j.resconrec.2016.03.026

Ciotta, M. N., Bayer, C., Ernani, P. R., Fontoura, S. M. V, Albuquerque, J. A., \& Wobeto, C. (2002). Acidificação de um Latossolo sob plantio direto. Revista Brasileira de Ciência do Solo, 26(4), 1055-1064. http://dx.doi.org/10.1590/S0100-06832002000400023

Cobo, J. G., Dercon, G., \& Cadisch, G. (2010). Nutrient balances in African land use systems across different spatial scales: a review of approaches, challenges and progress. Agriculture, Ecosystems \& Environment, 136(1-2), 1-15. http://dx.doi.org/10.1016/j.agee.2009.11.006

Cunha, J. F., Casarin, V., \& Prochnow, L. I. (2010). Balanço de nutrientes na agricultura brasileira. Informações Agronômicas, (135), 1-11.

Cunha, J. F., Casarin, V., \& Prochnow, L. I. (2011). Balanço de nutrientes na agricultura brasileira no período de 1988 a 2010. Informações Agronômicas, 19, 1-7.

Cunha, J. F., Francisco, E. A. B., \& Prochnow, L. I. (2018). Balanço na agricultura brasileira no perído de 2013 a 2016. Informações Agronômicas, 162(19), 3-14.

Cunha, J. F., Francisco, E. A. B., Casarin, V., \& Prochnow, L. I. (2014). Balanço de nutrientes na agricultura brasileira - 2009 a 2012. Informações Agronômicas, 3(145), 1-13.

Dvarskas, A. (2018). Experimental ecosystem accounting for coastal and marine areas: a pilot application of the SEEA-EEA in Long Island coastal bays. Marine Policy, 100, 1-11. http:// dx.doi.org/10.1016/j.marpol.2018.11.017

Edens, B., \& Graveland, C. (2014). Experimental valuation of Dutch water resources according to SNA and SEEA. Water Resources and Economics, 7, 66-81. http://dx.doi.org/10.1016/j. wre.2014.10.003

Feijó, C. A., \& Ramos, R. L. O. (2017). Contabilidade Social - a nova referência das Contas Nacionais do Brasil (4. ed.). Rio de Janeiro: Campus, Elsevier.

Fernandes, M. S. (2006). Nutrição mineral de plantas (1. ed.). Viçosa: Sociedade Brasileira de Ciência do Solo. 
Ferreira, M. M. (2010). Caracterização física do solo. In Q. J. Van Lier (Ed.), Física do solo (1. ed., pp. 1-27). Viçosa: Sociedade Brasileira de Ciência do Solo.

Filho, F. R. F., Ribeiro, V. Q., Rocha, M. D. R., Silva, K. J. D. E., Nogueira, M. D. S. D. R., \& Rodrigues, E. V. (2011). Feijão-Caupi no Brasil: Produção, Melhoramento Genético, Avanços e Desafios. In F. R. F. Filho (Ed.), Embrapa Meio-Norte (1. ed.). Teresina: Embrapa Meio-Norte.

G1. (2016). Plantas aquáticas denunciam poluição em lagoa na Serra, ES. G1. Recuperado em 23 de setembro de 2020, de http://g1.globo.com/espirito-santo/noticia/2016/07/plantasaquaticas-denunciam-poluicao-em-lagoa-na-serra-es.html

G1. (2018). Prefeitura retira uma tonelada de peixes mortos do Rio Tietê em Sabino. G1. Recuperado em 23 de setembro de 2020, de https://g1.globo.com/sp/bauru-marilia/noticia/2018/12/05/ mortandade-de-peixes-no-rio-tiete-preocupa-moradores-de-sabino.ghtml

Gitti, D. C. (2013). Manejo da adubação do milho safrinha. In Fundação MS (Ed.). Tecnologia e Produção: Milho Safrinha e Culturas de Inverno (pp. 12-30). Maracaju: Fundação MS. Recuperado em 23 de setembro de 2020, de http://www.fundacaoms.org.br/tecnologiaproducao-milho-safrinha-2014

Gonzalez, D. J. V., Sinobas, L. R., Marcos, L. G., \& Calvo, R. S. (2016). Application of the System of Environmental Economic Accounting for Water SEEAW to the Spanish part of the Duero basin: lessons learned. Science of the Total Environment, 563(4), 611-622.

Gundimeda, H., Sukhdev, P., Sinha, R. K., \& Sanyal, S. (2007). Natural resource accounting for Indian states - Illustrating the case of forest resources. Ecological Economics, 61(4), 635649. http://dx.doi.org/10.1016/j.ecolecon.2006.07.035

Gutiérrez-Martín, C., Borrego-Marín, M. M., \& Berbel, J. (2017). The economic analysis ofwater use in the water framework directive based on the system of environmental-economic accounting for water: A case study of the Guadalquivir river basin. Water, 9(3), http://dx.doi. org/10.3390/w9030180

Haripriya, G. S. (2001). Integrated Environmental and Economic Accounting: An application to the forest resources in India. Environmental and Resource Economics, 19(1), 73-95. http:// dx.doi.org/10.1023/A:1011180604458

Instituto Brasileiro de Geografia e Estatística - IBGE (2016b). Produção Agrícola Municipal, 2015. Rio de Janeiro: IBGE.

Instituto Brasileiro de Geografia e Estatística - IBGE. (2016a). Contas Nacionais Trimestrais. Rio de Janeiro: IBGE.

Instituto Brasileiro de Geografia e Estatística - IBGE. (2016c). Sistema de Contas Nacionais: Brasil 2010-2014. Rio de Janeiro: IBGE.

Instituto Brasileiro de Geografia e Estatística - IBGE. (2020). Contas de Ecossistemas: o uso da terra nos biomas brasileiros : 2000-2018. Rio de Janeiro: IBGE.

Kuznets, S. (1968). Toward a theory of economic growth with reflections on the economic growth of modern nations. New York: Norton.

Lamera, J. A., Bonjour, S. C. M., \& Marcos, A. M. R. (2006). O crédito rural oficial e a agricultura de Mato Grosso: 1993 a 2001. Anais Do XLIV Congresso da Sober (pp. 1-20). Fortaleza: Universidade Federal do Ceará.

Lamond, R. E., \& Wesley, T. L. (2001). Adubação nitrogenada no momento certo para soja de alta produtividade. Informações Agronômicas, 95(1), 6-7. 
Lange, A., Carvalho, J. L. N., Damin, V., Cruz, J. C., \& Marques, J. J. (2006). Alterações em atributos do solo decorrentes da aplicação de nitrogênio e palha em sistema semeadura direta na cultura do milho. Ciência Rural, 36(2), 460-467.

Lenzen, M., \& Schaeffer, R. (2004). Environmental and social accounting for Brazil. Environmental and Resource Economics, 27(2), 201-226. http://dx.doi.org/10.1023/B:EARE.0000017281.24020.49

Lindhjem, H., Skjelvik, J. M., Eriksson, A., Terhi, F., \& Hansen, L. P. (2009). The use of economic instruments in Nordic environmental policy 2006-2009. Copenhagen: Nordisk Ministerråd. https://doi.org/10.1017/CBO9781107415324.004

MacDonald, G. K., Bennett, E. M., Potter, P. A., \& Ramankutty, N. (2011). Agronomic phosphorus imbalances across the world's croplands. Proceedings of the National Academy of Sciences of the United States of America, 108(7), 3086-3091. http://dx.doi.org/10.1073/pnas.1010808108

Maldonado, J. H., \& Lachaud, M. A. (2011). Aproximacion calculo del crecimiento real de Colombia: aportes metodologicos para la inclusión en las cuentas nacionales de los impactos del agotamiento del carbón y del gas natural. Revista de Economía Del Rosario, 14(1), 1-29.

Manzatto, C. V., \& Freitas Junior, E. F., \& Peres, J. R. R. (2002). Uso Agrícola dos Solos Brasileiros. Rio de Janeiro: Embrapa Solos.

Marcos, R. P., Azzoni, C. R., \& Guilhoto, J. J. M. (2009). Decomposição da queda na desigualdade de renda no Brasil: uma análise via Matriz de Contabilidade Social para os anos de 2004 e 2009. Núcleo de Economia Regional e Urbana da Universidade de São Paulo, 5(2014), 1-33.

Mardones, C., \& Saavedra, J. (2011). Matriz de Contabilidad Social extendida ambientalmente para analises economico de la region Del Bio Bio. Revista de Análisis Económico, 26(1), 17-51.

Mazzanti, B., Bonamini, I., Checcucci, G., Fiumi, L., Consumi, F., Bartalesi, S., \& Montini, G. (2014). The UN System for Environmental-Economic Accounts for Water (SEEA-W) and groundwater management: the experience of the Arno River Basin Authority within the PAWA project. Italian Journal of Groundwater, 137(3), 73-77. http://dx.doi.org/10.7343/AS-086-14-0113

McArthur, J. W., \& McCord, G. C. (2017). Fertilizing growth: agricultural inputs and their effects in economic development. Journal of Development Economics, 127, 133-152. https://doi. org/10.1016/j.jdeveco.2017.02.007

Meurer, E. J. (2006). Fundamentos de química do solo. Porto Alegre: Evangraf.

Meurer, E. J. (2007). Fatores que influenciam o crescimento e o desenvolvimento das plantas. In R. F. Novais, V. H. Alvarez, V. N. F. Barros, R. L. F. Fontes, R. B. Cantarutti, \& J. C. L. Neves (Eds.), Fertilidade do solo (1. ed.). Viçosa: Sociedade Brasileira de Ciência do Solo.

Miller, R. E., \& Blair, P. D. (2009). Input-output analysis: foundations and extensions (2nd ed). Cambridge: Cambridge University Press.

Morilla, C. R., Díaz-Salazar, G. L., \& Cardenete, M. A. (2007). Economic and environmental efficiency using a social accounting matrix. Ecological Economics, 60(4), 774-786. http:// dx.doi.org/10.1016/j.ecolecon.2006.02.012

Oliveira, E. C. A., Freire, F. J., Oliveira, R. I., Freire, M. B. G. S., Neto, D. E. S., \& Silva, S. A. M. (2010). Extração e exportação de nutrientes por variedade de cana-de-açúcar cultivdades sob irrigaçaõ plena. Revista Brasileira de Ciência do Solo, 34(4), 1343-1352. http://dx.doi. org/10.1590/S0100-06832010000400031

Organização das Nações Unidas - ONU. (2009). System of National Accounts 2008. In Organização das Nações Unidas (Ed.), Non-extensive entropy econometrics for low frequency series. Poland: De Gruyter Open Poland. https://doi.org/10.1515/9783110605914-007 
Organização das Nações Unidas - ONU. (2012). System of Environmental- Economic Accounting for Water. In Organização das Nações Unidas (Ed.), Trauma management in orthopedics. Poland: De Gruyter Open Poland. https://doi.org/10.1007/978-1-4471-4462-5

Organização das Nações Unidas - ONU. (2014). System of Environmental-Economic Accounting 2012: Central Framework. In Organização das Nações Unidas (Ed.), White cover publication (Issues 10-11). Poland: De Gruyter Open Poland. https://doi.org/ST/ESA/STAT/Ser.F/109

Pará. Fundação Amazônica de Amparo a Estudos e Pesquisas do Pará - FAPESPA. (2015). Medidas da atividade econômica no Estado do Pará: Tabelas de Recursos e Usos (TRU), Matriz Insumo- -Produto (MIP) e Matriz de Contabilidade Social (MCS) do estado do Pará. Publicação Oficial FAPESPA, Belém.

Paulani, L. M., \& Braga, M. B. (2012). A nova contabilidade social: uma introdução à macroeconomia (4. ed.). São Paulo: Saraiva.

Pyatt, G., \& Round, J. I. (1979). Accounting and fixed price multipliers in social accounting matrix framework. Economic Journal, 89(356), 850-873.

Repetto, R., Magrath, W., Wells, M., Beer, C., \& Rossini, F. (1989). Wasting assets: natural resources in the national income accounts. Washington, DC: World Resources Institute.

Resende, A. S., Xavier, R. P., Oliveira, O. C., Urquiaga, S., Alves, B. J. R., \& Boddey, R. M. (2006). Long-term effects of pre-harvest burning and nitrogen and vinasse applications on yield of sugar cane and soil carbon and nitrogen stocks on a plantation in Pernambuco, N.E. Brazil. Plant and Soil, 281(1-2), 339-351. http://dx.doi.org/10.1007/s11104-005-4640-y

Rodrigues Alves, B. J., Zotarelli, L., Marques Fernandes, F., Heckler, J. C., Tavares De Macedo, R. A., Boddey, R. M., Jantalia, C. P., \& Urquiaga, S. (2006). Fixação biológica de nitrogênio e fertilizantes nitrogenados no balanço de nitrogênio em soja, milho e algodão. Pesquisa Agropecuária Brasileira, 41(3), 449-456. http://dx.doi.org/10.1590/S0100-204X2006000300011

Round, J. (2003). Social accounting matrices and sam-based multiplier analysis. In F. Bourguignon \& L. A. P. Silva (Eds.), The impacts of economic policies on poverty and Income distribution: evaluation techniques and tools. Washington, DC: World Bank.

Santana, A. C. (1994). A dinâmica do complexo agroindustrial e o crescimento no Brasil. Viçosa: Universidade Federal de Viçosa.

Santana, A. C. (2005). Elementos de economia, agronegocio e desenvolvimento local. Belém: Universidade Federal Rural da Amazônia.

Schultz, T. W. (1965). A tranformação da agricultura tradicional. Rio de Janeiro: Zahar Editores.

Setlhogile, T., Arntzen, J., \& Pule, O. B. (2017). Economic accounting of water: the Botswana experience. Physics and Chemistry of the Earth, 100, 287-295. http://dx.doi.org/10.1016/j. pce.2016.10.007

Sfredo, G. J. (2008). Soja no Brasil: calagem, adubação e nutrição mineral. Warta: Embrapa Soja. Sheldrick, W. F., Syers, J. K., \& Lingard, J. (2003). Soil nutrient audits for China to estimate nutrient balances and output/input relationships. Agriculture, Ecosystems \& Environment, 94(3), 341-354. http://dx.doi.org/10.1016/S0167-8809(02)00038-5

Silva, E. B., Neto, J. R. de A., \& Lima, B. P. (2018). Similaridade de Eutrofização das Águas Superficiais da Bacia do Alto Jaguaribe, Ceará. Revista Engenharia Na Agricultura, 25(4), 343-351. https://doi.org/https://doi.org/10.13083/reveng.v26i3.919 
Sociedade Brasileira de Ciência do Solo - SBCS. (2004). Manual de adubação e de calagem para os estados do Rio Grande so Sul e Santa Catarina. Viçosa: Sociedade Brasileira de Ciência do Solo.

Sousa, D. M. G., Miranda, L. N., \& Oliveira, S. A. (2007). Acidez do solo e sua correção. In R. F. Novais, V. H. Alvarez, V. N. F. Barros, R. L. F. Fontes, R. B. Cantarutti, \& J. C. L. Neves (Eds.), Fertilidade do solo (1. ed.). Viçosa: Sociedade Brasileira de Ciência do Solo.

Stiglitz, J. E., Sen, A., \& Fitoussi, J.-P. (2009). Report by the commission on the measurement of economic performance and social progress. RatSWD, (162), 1-73. http://dx.doi.org/10.2139/ ssrn. 1714428

Stone, R. (1985). The disaggregation of the household sector in the national accounts. In G. Pyatt \& J. I. Round (Eds.), Social accounting matrices: a basis for planning. (pp. 146-185). Washington, DC: World Bank.

The World Bank. Databank. (2017). World Development Indicators. Recuperado em 23 de setembro de 2020, de http://databank.worldbank.org/data/reports.aspx?source=2\&series=AG.LND. AGRI.ZS\&country=WLD\#

Urani, A., Moreira, A., Ferreira, M. A. R., \& Gottshalk, H. (1994). Construção de uma Matriz de Contabilidade Social para o Brasil. Brasília: IPEA.

Tongeren, J., Schweinfest, S., Lutz, E., Luna, M. G., \& Martin, F. G. (1991). Integrated Environmental and Economic Accounting: a Case Study for Mexico (Working Paper). Washington, DC: World Bank. Recuperado em 23 de setembro de 2020, de http://millenniumindicators.un.org/ unsd/envAccounting/ceea/archive/Energy/integrated_environmental.pdf

Vardon, M., Bass, S., Ahlroth, S., \& Rujis, A. (2017). Forum on Natural Capital Accounting for Better Policy Decisions: talking stock and moving forward. Washington, DC: World Bank.

Vitousek, P. M., Naylor, R., Crews, T., David, M. B., Drinkwater, L. E., Holland, E., Johnes, P. J., Katzenberger, J., Martinelli, L. A., Matson, P. A., Nziguheba, G., Ojima, D., Palm, C. A., Robertson, G. P., Sanchez, P. A., Townsend, A. R., \& Zhang, F. S. (2009). Nutrient imbalances in agricultural development. Science, 324(5934), 1519-1520. http://dx.doi.org/10.1126/science.1170261

Yamada, T., \& Lopes, A. S. (1998). Balanço de nutrientes na agricultura Brasileira. Informações Agronômicas, (84), 1-8.

Zylbersztajn, D., Neves, M. F., \& Caleman, S. M. Q. (2015). Gestão de Sistemas de Agronegócios. (1. ed.). São Paulo: Atlas. 